\title{
A review of microstructure evolution during ultrasonic additive manufacturing
}

\author{
Dezhi Li ${ }^{1}$
}

Received: 26 August 2020 / Accepted: 1 December 2020 / Published online: 22 January 2021

(C) The Author(s) 2021

\begin{abstract}
Ultrasonic additive manufacturing (UAM) is a solid-state metal additive manufacturing process, with the combination of layer by layer ultrasonic seam welding and $\mathrm{CNC}$ machining. Due to the friction and deformation at the bonding interface, the ultrasonic softening effect and temperature generated, the microstructure of the substrate materials is evolving constantly. In this paper, in order to better understand the bonding mechanisms, the good practice and the capability of UAM, and the influence of different key process parameters on bonding quality, the microstructure evolution during UAM is reviewed in detail. Defects can be generated at the UAM bonding interface, but by choosing the right material combination and the right process parameters, defects can be reduced to minimum. Plastic deformation is very important for the bonding between layers during UAM, and plastic flow is important for redistribution of oxide layer, forming of mechanical interlocks, filling micro-valleys on the mating surface, and filling the gaps when embedding elements. UAM process can cause recrystallization and grain refinement at the welding interface and the intimate bulk materials around, and it will also gradually change the texture from rolling texture to shear texture. In the meantime, when further layers of materials are deposited on the top of the existing part, the microstructure will have some accumulative change. In order to reduce the defects number and increase the strength, sometimes, heat treatment needs to be carried out to the as-deposited parts, which will change the microstructure as well. Finally, the relevant research is summarised and the perspectives of further research are recommended.
\end{abstract}

Keywords Ultrasonic additive manufacturing (UAM) · Ultrasonic consolidation (UC) · Microstructure evolution · Linear weld density $\cdot$ Plastic flow $\cdot$ Recrystallization $\cdot$ Post-process heat treatment

\section{Introduction}

Ultrasonic additive manufacturing (UAM), previously ultrasonic consolidation (UC), is a solid-state metal additive manufacturing process, in which ultrasonic seam welding process is used to build thin layer of metal foils layer by layer, and by combining with computer numerical control (CNC) machining and additional elements embedding, a complex, hollow and smart structure can be built. UAM is therefore a hybrid of additive and subtractive manufacturing process, as shown in Fig. 1 [1]. CNC is used to machine the contour of the part after certain layers of deposition, before further layers are deposited and so on. UC process was invented and patented by Dawn White [2]. UAM operates at temperatures much

Dezhi Li

Dezhi.li@warwick.ac.uk

1 WMG, University of Warwick, Coventry CV4 7AL, UK lower than the melting temperatures of the substrate materials, usually $0.3-0.5 T_{\mathrm{m}}$. There are many metal AM processes [3], including sheet material based: UAM; powder bed-based: selective laser melting (SLM) $[4,5]$ or powder bed fusionlaser beam (PBF-LB), electron beam melting (EBM) [6]; binder jetting based: metal binder jetting and sintering [7]; blown powder-based: laser metal deposition (LMD) [8] or direct energy deposition (DED) or Laser engineered net shaping (LENS) [9]; and wire-based: wire + arc additive manufacturing (WAAM) [10]. UAM has several advantages over other AM technologies, such as ability to fabricate dissimilar materials and embed elements, higher deposition rate (against most of other AM processes, except wire + arc additive manufacturing), lower working temperatures and low residual stress and distortion.

UAM has been used to fabricate soft materials, such as $\mathrm{Al}$ alloys [11,12], harder materials, such as copper [13-15], nickel [16], steel [17, 18] and titanium [19-21], dissimilar materials, such as Al-Ti [21], Al-Cu [15], Al-steel [22], Al-NiTi 
Fig. 1 The schematic diagram of the UAM process [1]

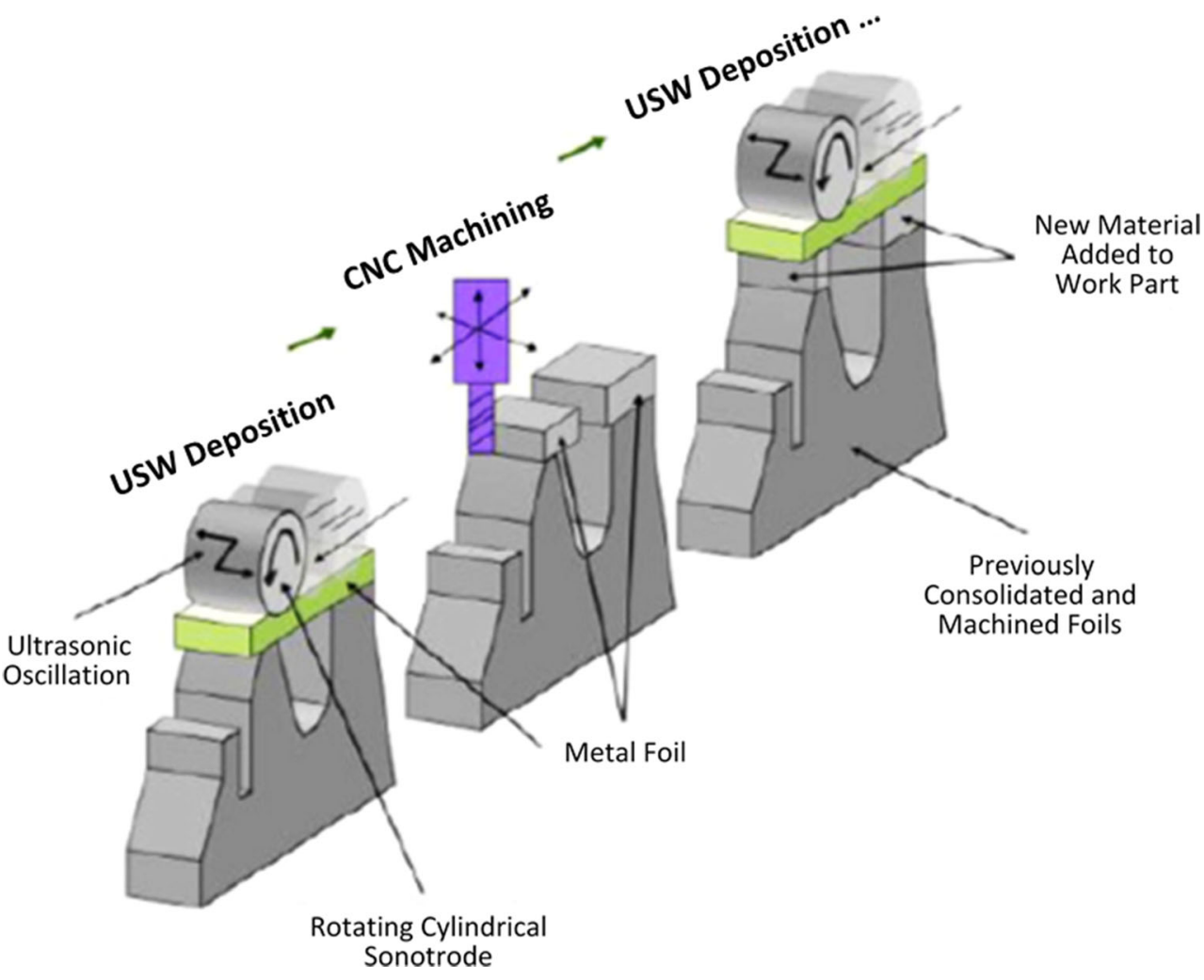

[23, 24], Al-MetPreg (a fibre-reinforced aluminium) [25-27] and Ni-steel [18] and metal matrix composite with embedded elements, such as SiC fibres [28, 29], shape memory alloy fibres [30], dielectric materials (used in printed circuit board) [31], electronic circuitry [32], glass fibres and fibre optic sensors [33-35] and carbon fibres [36].

During UAM process, due to the friction and highfrequency shear deformation at the mating interface, the high strain caused by plastic deformation, the ultrasonic softening effect, temperature generated and subsequent heat treatment, the microstructure of the materials, especially at the welding interfaces, is evolving at different stages. Microstructure, including defects, plastic flow, grain size, grain orientation and distribution, material phases and texture, is very important for UAM-fabricated parts, as to mechanical properties. Study of the microstructure evolution at the bonding interface is critical for the understanding of the ultrasonic bonding mechanism. The microstructure of the UAM parts has been studied by many researchers for different substrate materials and combinations, but has not been systematically reviewed. There has been several review papers on UAM [37,38], but they did not cover the microstructure evolution in detail. It is believed that a review on the microstructure evolution will help to understand the bonding mechanisms, the good practice, the capability and the influence of different process parameters on build quality of UAM. In this paper, it will be reviewed from the following four aspects: defects at the bonding interface, plastic flow during UAM, microstructure and texture evolution during UAM and influence of post-weld heat treatment on microstructure.

\section{Defects in ultrasonic additive manufactured parts}

It is generally believed that during UAM process, the applied normal force/pressure will compress the foils and bring the asperities on the mating surfaces into contact; the applied ultrasonic oscillation will initially shear the mating asperities and later the bonded interface; the applied oscillation will also break the oxide and contaminants on the surface and redistribute them in the materials around the interface to create some clean mating interface; the bonding at the interface is generated by shear deformation, inter-diffusion and sometimes mechanical interlocking. Void formation at the weld interface is attributed to surface asperities of the original foils and those on the top of the foil just deposited resulting from compression and shear deformation induced by the sonotrode [39-43]. Welding defects at the interface can also be from the unbroken oxides at the original foil surface. Johnson [44] pointed out that surface oxides existing at the welding interface were expected to have negative impact on the mechanical strength. Because defects are areas not bonded and they are stress concentration locations for crack propagation, they need to be eliminated or reduced as much as possible to increase the strength of the UAM built parts. For UAM, to eliminate the 
defects is very challenging, and the way to reduce the defects is to introduce enough plastic deformation/flow to fill the voids generated at the bonding interface and to break the oxides into pieces as small as possible and then redistribute them to the materials around the interface with suitable process parameters.

At early stage of the development of ultrasonic consolidation (UC)/ultrasonic additive manufacturing (UAM), mainly aluminium alloys, such as Al 3003 and Al 6061, are used as the deposition material, because they are soft and easier to be bonded together by ultrasonic welding with a high linear weld density (LWD), which is defined by the ratio of the bonded interface length to the total interface length in a cross-section. However, with further development, mainly the introduction of very high power ultrasonic additive manufacturing (VHP UAM) machines [45], due to the increased maximum power, applied normal force and vibration amplitude, nowadays more harder materials can also be used for UAM, such as copper [13-15], nickel [16], steel [17] and titanium [19-21]. Two conditions are necessary for metallurgical bonding to occur: oxide removal and asperity collapse (plastic deformation) $[46,47]$. For harder materials, to deform and collapse the surface asperities are more difficult and need more energy. Such that to achieve a high bonding density, high oscillation amplitude and/or high normal force will be required.

UAM is also capable of joining dissimilar or multiple materials, and it has been demonstrated in several researches $[18$, $21,22,26,27,48-52]$. Obielodan [26] studied the feasibility of joining multi-materials, including $\mathrm{Al}, \mathrm{Ni}, \mathrm{Ti}, \mathrm{Ta}$, stainless steel, MetPreg, Ag, Mo and $\mathrm{Cu}$, by $\mathrm{UC}$, and the results showed that all FCC materials and some other material combinations could be bonded well by UC with a good LWD. An example is shown in Fig. 2, but for some other combinations, an $\mathrm{Al} 1100$ interlayer was required. Janaki Ram et al. [50] also studied joining between Al 3003 H18 and different other

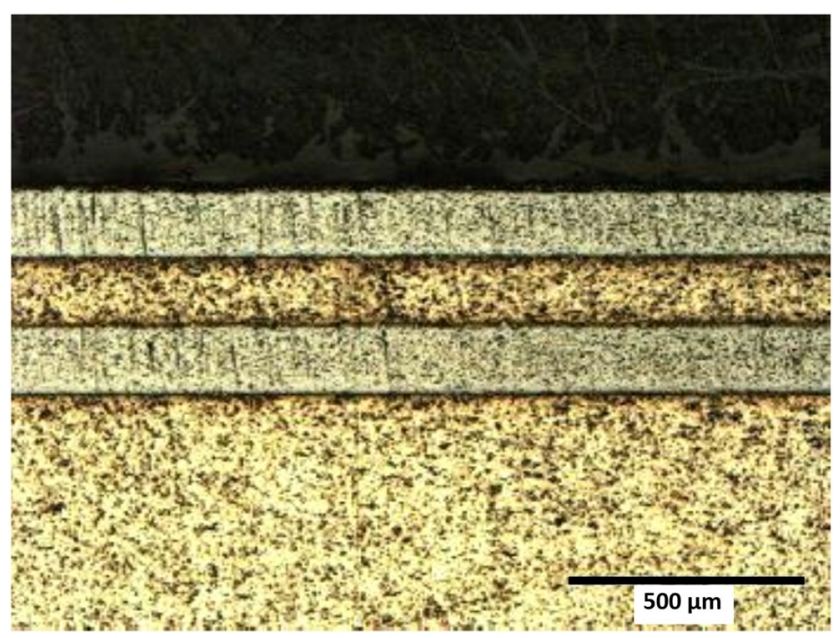

Fig. $2 \mathrm{Ta} / \mathrm{Al}$ 3003/Ta on Al 3003-H14 substrate [26] materials, including brass, Inconel 600, stainless steel 347, stainless steel 304 mesh, MetPreg. It is generally believed that it is easier to join a soft material to a harder material than to join a harder material to itself. This is why a softer interlayer can be used to improve the bonding between two harder material layers, as demonstrated by Kuo et al. [18] using a Ni interlayer to join 4130 steel layers and by Wolcott et al. [21] using an Al 1100 interlayer to join commercially pure Ti layers. This mechanism of using a soft interlayer to join hard materials has also been used for ultrasonic spot welding [53, 54]. When a soft material and a harder material are bonded together by UAM, they can be deposited directly layer by layer, or they can be deposited indirectly: two layers (one bilayer) are deposited together. As to the indirect deposition, there are two different strategies for the bilayer: (1) soft layer on the top of the harder layer and (2) the harder layer on the top of the soft layer. It was proved that strategy 2 was better than strategy 1 as to bonding density and joint quality. Janaki Ram et al. [50] used strategy 1 and found out that a lot of defects formed between the harder layer and the previously as-deposited soft layer; however, Kuo et al. [18] and Wolcott et al. [21] found out that by using strategy 2 , good welding density could be achieved at all interfaces. The influence of two indirect deposition strategies on the bonding density and joint quality can be explained below. It had been demonstrated that during UAM process, when a soft material was in contact with the sonotrode, the texture from the sonotrode would be largely transferred to the surface of the soft material, which made the surface rougher with peaks and valleys in microscale, but when a hard material was in contact with the sonotrode, much less texture would be transferred, leaving hardly deformed and much smooth surface [42, 44]. Research also showed that when the sonotrode was in contact with a soft material, during UAM process, the soft material would be deformed and grain-refined, which would increase its hardness [43]; however, when the sonotrode was in contact with a hard material (if the power was not high enough), the hard material would not have any significant deformation and hardening [21]. It can be seen that for strategy 2, at the new/ previous deposition interface, it has unhardened soft material on the top of the previous deposited smooth hard material. The soft material can be heavily deformed to have large area of intimate contact with the hard material and to flow into the surface micro-valleys of the hard material to eliminate voids. As a result, a high bonding density and a good joint quality will be achieved. However, for strategy 1 , at the new/previous deposition interface, it is the hard material on the top of the roughened and hardened soft material from the previous deposition. There are many micro- peaks and valleys on the previous deposited surface, but the hard material cannot be deformed enough at the power level applied to close the voids, leaving defects at the interface. For better understanding of the indirect deposition mechanism, further study is required. 
Two main bonding mechanisms are proposed for UC: inter-diffusion and mechanical interlocking. Bonding occurs by local grain boundary migration, which allows diffusion and atom interlocking across the contact between two clean surfaces [55].

It is generally believed that the increase of ultrasonic oscillation amplitude, normal force and preheat temperature, and the decrease of welding speed will increase the LWD and the mechanical strength of the fabricated parts [12, 40, 56-58]. Janaki Ram et al. [40] systematically studied the influence of process parameters of $\mathrm{UC}$ on the void formation at the welding interface. They categorised the voids at the UAM interfaces into three types: linear-type, parabola-like and point-like. The parabola-like voids are normally generated due to the existing of large micro-valleys on the rough surface induced by the sonotrode during the previous deposition. During the following deposition, if there is not enough material flowed into the micro-valleys, then parabola-like voids will be generated. The results showed that an increase of oscillation amplitude, normal force, process temperature, reduce of welding speed and surface machining after ultrasonic deposition can reduce the number of voids and increase LWD. However, the influence of these factors needs to be limited to the level that will result in material oxidation and/or fatiguerelated embrittlement. Janaki Ram et al. [40] demonstrated that with the optimised process parameters, the LDW of Al $3003 \mathrm{H} 18$ could reach as high as $98 \%$. Additional heating with heat plate can reduce the level of voids at the welding interface, due to the increased process temperature and material plasticity. Results from Kulakov and Rack [28] showed that the normal load and the vibrational amplitude have a significant influence on LWD, whilst the sonotrode rotational velocity (welding speed) has only a marginal effect. Sriraman et al. [59] presented that by using VHP UAM, the void level at the interface of $\mathrm{Al} 6061 \mathrm{H} 18$ and $\mathrm{C} 11000$ (also called $\mathrm{Cu} 110$, hard temper) parts can be greatly reduced, compared to the parts built by conventional UAM.
General speaking, soft materials are more easy to be bonded with less voids by UAM. Figure 3 shows the cross-sections of Al parts made of multi-layers of $\mathrm{Al} 3003$ with two different heat treatments. It can be seen that the part made of the harder grade, Al $3003 \mathrm{H} 18$, had much more voids at the welding interfaces than that made of the softer grade, Al $3003 \mathrm{O}$. In order to reduce the numbers of voids during the welding of harder materials, more energy will be required, with possible higher pressure and oscillation amplitude.

Friction is very important for UAM. During UAM process, in order to transfer the energy efficiently from the sonotrode to the bonding interface, the sonotrode needs to grip the top foil firmly with no or minimum slippage between them. For this reason, the surface roughness and texture of the sonotrode are very important, and it is a big factor that influences the LWD and bonding quality. Study from Li and Soar [39] showed that the surface roughness of the sonotrode was very important for UAM. Figure 4 shows the cross-sections of samples when a worn sonotrode ( $\mathrm{Ra}, 3.44 \mu \mathrm{m})$ and an electric discharge machining (EDM) resurfaced sonotrode ( $\mathrm{Ra}, 6.28 \mu \mathrm{m}$ ) were used. The results showed that when the sonotrode was worn, the surface roughness was low, and it would not be able to grip the top foil well and pass the ultrasonic energy to the welding interface efficiently. As a result, more defects were generated at the welding interface, the LWD between each layer was poor, and the bonding strength between each foils was weak. Similarly, research from Wolcott et al. [41] showed that by increasing the surface roughness of the sonotrode from 7 to $14 \mu \mathrm{m}(\mathrm{Ra})$, the bonding strength at the foil interface could be further increased. They demonstrated that a flattening pass (using $\mathrm{CNC}$ machining to smooth the roughened top surface of the as-deposited foil) before further deposition can also improve bond strength. However, sonotrode can also introduce roughness/texture on the top surface of deposited foil. Friel et al. [42] and Johnson [44] studied the influence of two sonotrodes, one surface textured by laser etching (rougher and uneven, $\mathrm{Ra}, 12.94 \mu \mathrm{m}$ ) and the other by EDM (smoother and

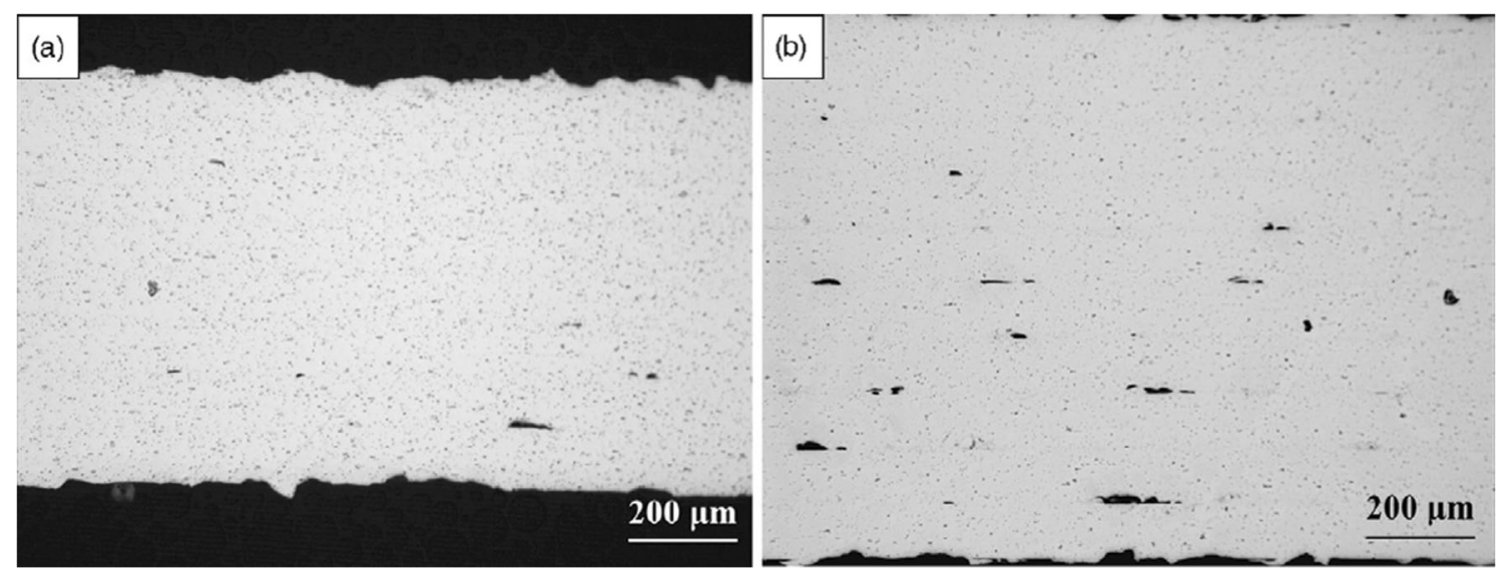

Fig. 3 Cross-section microstructures of Al alloy foils consolidated at 155.8 MPa pressure, $10.4 \mu \mathrm{m}$ amplitude and $34.5 \mathrm{~mm} / \mathrm{s}$ consolidation speed: a Al 3003 O, 8 layers and b Al 3003 H18, 10 layers [39] 

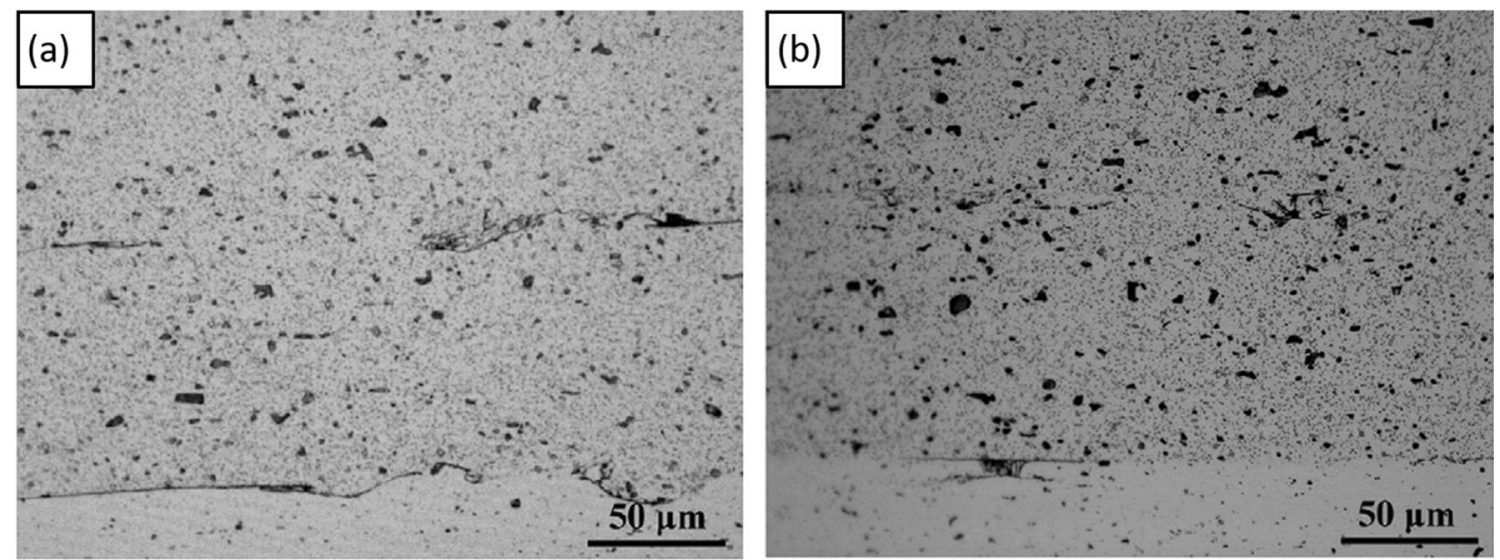

Fig. 4 Cross-sections of samples made with the worn sonotrode (a ) and the EDM-resurfaced sonotrode (b) with weld speed at $34.5 \mathrm{~mm} / \mathrm{s}$, pressure at 155.8 MPa, and amplitude at $12.3 \mu \mathrm{m}$. Modified from [39]

even, Ra, $5.9 \mu \mathrm{m}$ ), on top surface topography, bonding quality and bonding strength. They found out the texture from the sonotrodes could be nearly $100 \%$ transferred to the foil surface when soft materials, such as $\mathrm{Al} 3003$, were deposited; however, when hard materials, such as Ti-6Al-4V, were deposited, much less texture had been transferred. Their results showed that when the laser-etched sonotrode was used to build $\mathrm{Al} 3003$ foils, more voids generated at the welding interfaces in the built parts, because the sonotrode was too rough and uneven. It is believed that for UAM, suitable sonotrode with the right surface texture and roughness needs to be chosen: if the surface roughness is too low, it will cause slippage between sonotrode and the top foil and lose energy; if the surface roughness is too high, it may introduce larger voids at the welding interfaces. $\mathrm{Li}$ and Soar [39] believed that at lower oscillation amplitudes, increasing the surface roughness had more negative effect, and at higher oscillation amplitudes, it had more positive effect to the welding strength. Because a higher roughness sonotrode will make the top surface of the just-deposited foil rougher with higher peaks and lower valleys in microscale, and in order to fill the micro-valleys in the next deposition, a higher ultrasonic energy with a higher oscillation amplitude will be required.

Janaki Ram et al. [40] have demonstrated that surface machining after foil deposition could reduce the surface roughness and increase the LWD of Al $3003 \mathrm{H} 18$ part greatly, but no mechanical test data available to confirm the influence of surface machining on the mechanical strength of the fabricated parts. However, it is not that the smaller the surface roughness the better the bonding density will be. Johnson [44] studied the influence of surface texture on the top surface of the bottom layer and the bottom surface of the top layer on the microstructure at the interface. Around $20 \mu$ was removed from the top surface of the first deposited layer by machining; then, four different surface textures, i.e., hand polish to $1 \mu$, rolled by the sonotrode at $500 \mathrm{~N}$ normal force but without ultrasonic oscillation, roughened with trenches about 3-5 $\mu$ along the rolling direction and roughened with trenches about
3-5 $\mu$ perpendicular to the rolling direction, were generated on the top surface of the machined bottom layer and the bottom surface of the top layer before the new layer was deposited on the top of the previous layer. The results showed that at the areas with polished texture, the bond line was straight and there was no obvious nano-grain refinement; at the areas with rolled texture, the microstructure with nano-grain refinement at the interface was similar with that for the deposition without surface machining and engineered texture; at the areas with trenches, there were also areas with nano-grain refinement and areas with improved oxide layer breaking and redistribution. Johnson's results showed that a relative rough surface at the welding interface was beneficial for good bonding, plastic deformation and grain refinement. The importance of surface roughness on interface grain refinement has been proved by Pal and Stucker [60] through simulation.

Voids can also be generated at the interface due to the uneven contact pressure from the sonotrode. Study of Kulakov and Rack [57] showed that defects at the edge and centre of the bonding interface were formed during ultrasonic consolidation of Al $3003 \mathrm{H} 18$. They believed that the formation of edge defects, as shown in Fig. 5, was attributed to the non-uniform strain state across the foil width, whilst the central defects were related to sonotrode-foil contact pressure variations following the sonotrode pattern. Due to the uneven contact pressure distribution at the bonding interface, more voids were reported existing at the edge of the deposition than those in the centre for Al $6061 \mathrm{H} 18$ parts fabricated by VHP UAM [59].

Since UAM is an additive layer manufacturing process with layers fabricated side-to-side and layer by layer, voids can also be affected by the building pattern or strategy. Wolcott et al. [41] studied the influence of the stacking sequence of foil layers on the void level and joint strength of ultrasonic consolidated Al $6061 \mathrm{H} 18$ parts. They found that the optimised layer stacking sequences should have a foil edge-to-edge overlap greater than $0.0635 \mathrm{~mm}$ using a 


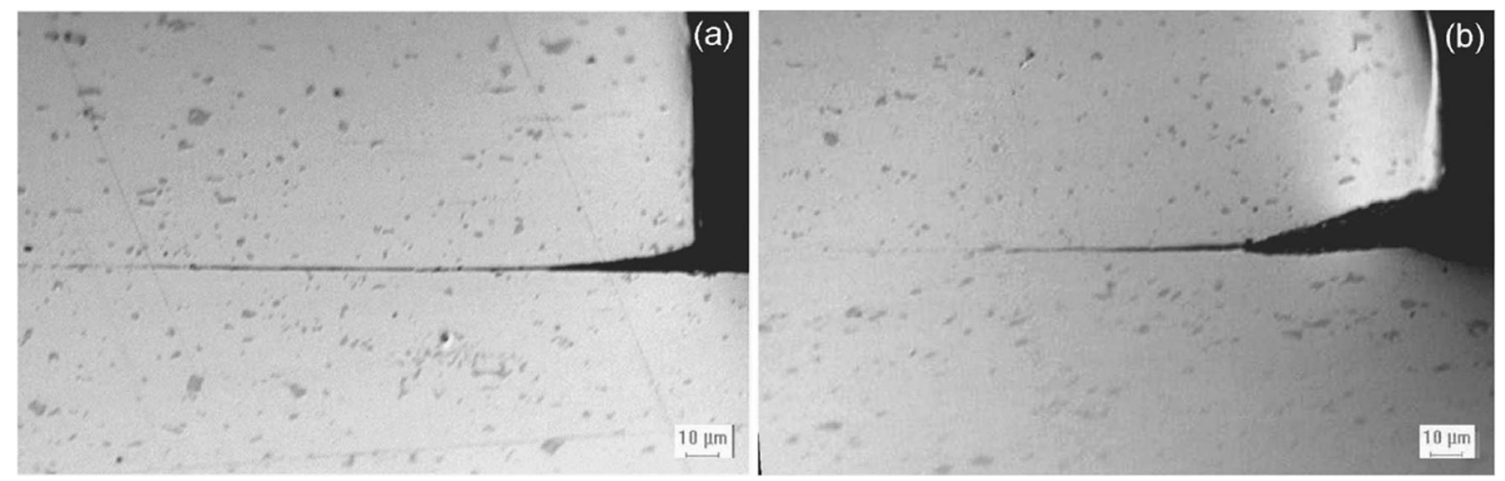

Fig. 5 Representative images of edge defects in samples with different process parameters, a $500 \mathrm{~N}, 12 \mu$ and $15.2 \mathrm{~mm} / \mathrm{s}$ and $\mathbf{b} 1000 \mathrm{~N}, 19 \mu$ and 76.2 $\mathrm{mm} / \mathrm{s}$ [57]

randomised stacking sequence. Obielodan and co-workers $[26,61]$ demonstrated that for ultrasonic consolidated $\mathrm{Al}$ 3003 H18 parts, the optimum edge-to-edge overlap distance was $0.07 \mathrm{~mm}$. Too much overlap may cause foil popping up or poor bonding and too large gap (opposite to overlapping) would leave large edge-to-edge gap defects, as shown in Fig. 6. These gap defects would cause reduced bonding area and act as locations for stress concentration, resulting reduced bonding strength. As to $50 \%$ overlapping layer-to-layer stacking and random stacking, no evidence could prove that one was better than the other.

\section{Plastic flow during UAM}

Due to the compression and cyclic shear plastic deformation, plastic flow happens at the welding interface. The plastic flow is very important for redistribution of oxide layer, forming of mechanical interlocks, filling the voids at the interface and embedding fibres and other elements.

There are different factors that can affect plastic flow at the interface, including substrate strength and hardness, interface surface roughness, UAM process parameters (especially

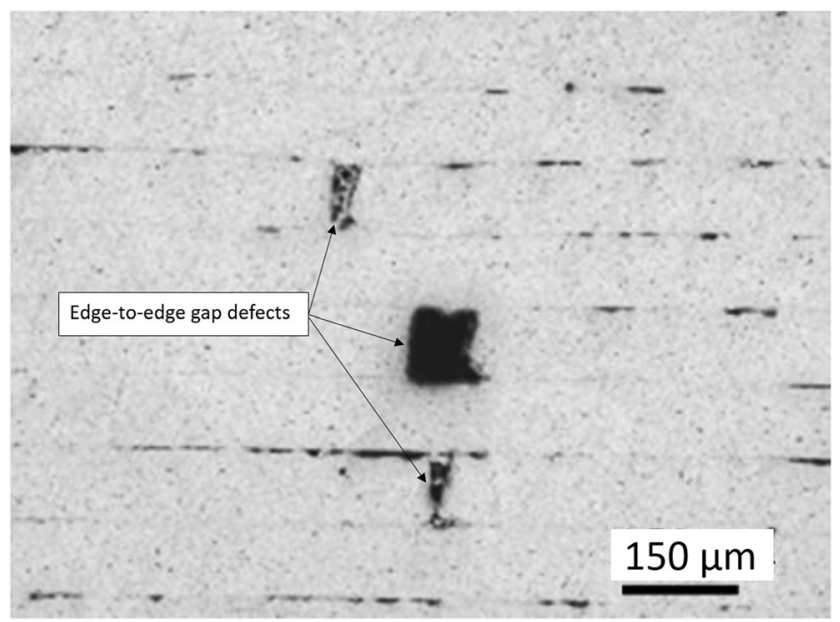

Fig. 6 Typical edge-to-edge gap defects in an UAM part [26] power), defects at interface, such as edge-to-edge gaps, and objects to be embedded.

Friction is very important for ultrasonic metal welding, which is used to break the oxide layer and introduce shear deformation to generate clean metal-to-metal mating interface. Using friction instead of molecule vibration is the main difference between ultrasonic metal welding and ultrasonic plastic welding. Such that surface roughness is very important for UAM and for the plastic flow during the process. If the surface is too smooth, then there will be little friction, shear deformation and plastic flow at the welding interface, and sometimes, the oxide layer at the interface will not be broken at all as shown by Johnson [44].

Plastic flow is related to plastic deformation and material's flow stress, so when a softer material and a harder material are joined together by UAM, there will be more plastic flow for the softer materials. This is especially obvious when a fibre/ fibres or other objects are being embedded between them. This has been shown by Yang et al. [16] and Johnson [44] when $\mathrm{SiC}$ fibres were embedded between $\mathrm{Cu}$ and $\mathrm{Al} 3003$ foils.

When fibres are being embedded between substrate materials, the materials will flow around the fibres to embed them, due to the ultrasonic softening and the compression and shear deformation, as shown in Fig. 7.

Normally, higher ultrasonic power will cause more plastic flow, and when the power is high enough and a proper interface existing, material flow turbulence can even be generated. During UAM fibre or object embedding process, when the applied ultrasonic power is not high enough, there will be no sufficient plastic flow around the fibres or objects and voids will be left around them, as shown by Johnson [44].

\section{Microstructure and texture change during UAM}

It was generally believed that UAM process only affects the microstructure and texture of the materials at the welding 

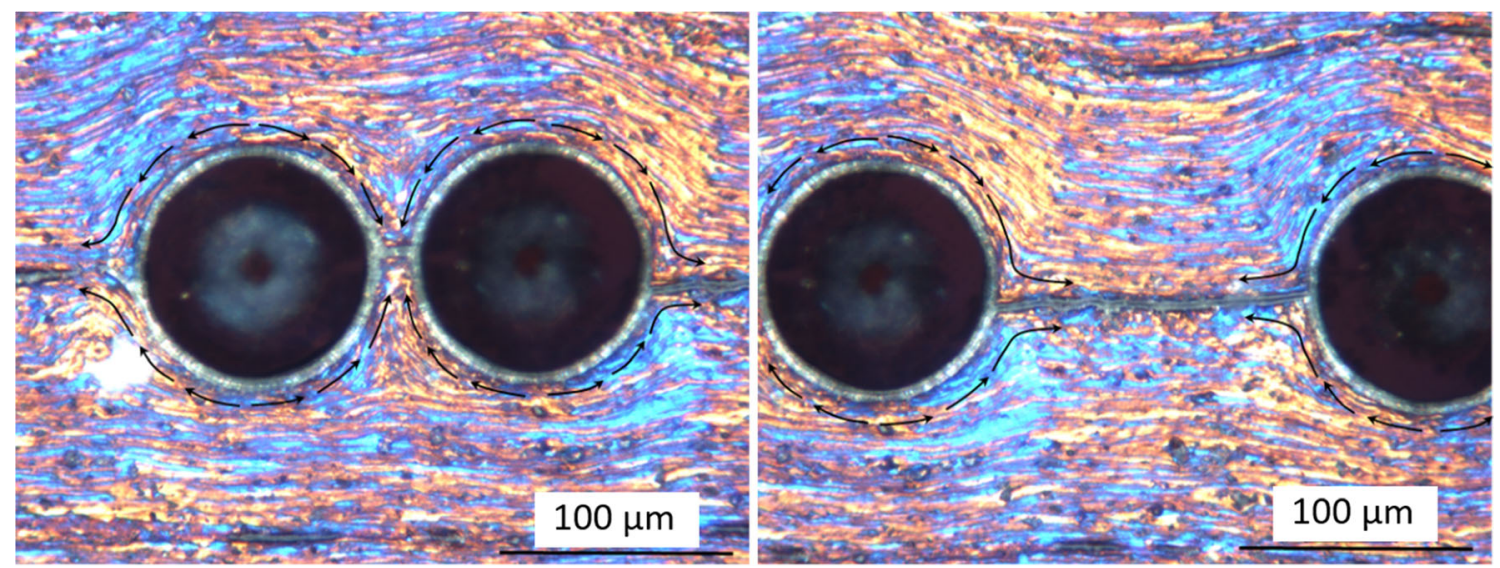

Fig. 7 Polarised optical images showing plastic flow of Al 3003 H18 during UAM SiC fibre embedding process

interface, and normally, the microstructure of the bulk material is intact after the UAM. However, study of Fujii et al. [62] showed that VHP UAM could change the microstructure and the texture of the materials in the bulk material as well. It is possible that this difference is related to the ultrasonic power level applied to the materials during the welding. When the power is high enough to severely deform the bulk materials, causing dynamic recrystallization and grain refinement, the microstructure and texture of the bulk material will be changed. When the power is only high enough to severely deform the materials at the welding interface, then only the microstructure and texture of the material at the welding interface will be changed. This influence is different to that for ultrasonic spot welding. For spot welding, due to small size of the sonotrode and larger deformation, more bulk material microstructure will be affected depending on the process parameters.

The mechanical strength of the bonded interface will not be determined solely by the interface void content but also by the overall microstructure of the materials at the interface, including the grain size, oxide disbursement, distribution of the intermetallic phases and dislocation content within the grains [56]. During UAM process, the materials to be deposited will be softened due to the ultrasonic energy applied [63] and plastically deformed. For a soft material, like $\mathrm{Al} 3003 \mathrm{O}$, the material deformation can be very large and the foils obviously become thinner (but elongated in the welding direction); however, for a hard material, such as $\mathrm{Ti}$, this deformation is normally small.

Due to the cyclic shear deformation, recrystallization and grain refinement, depending on the substrate materials and the process parameters used, there could be a hardening or softening effect on the materials, especially around the interface, after the UAM process. Work hardening has been reported by $\mathrm{Li}$ and Soar [64] on the Al $3003 \mathrm{O}$ and $\mathrm{Al} 6061 \mathrm{O}$ substrates, when SiC fibres and optical fibres were embedded by the UAM process. They found that the work hardening and grain/sub-grain refinement followed the Hall-Petch relationship. Sriraman et al. [14] used very high power UAM (VHP UAM) to bond $150 \mu \mathrm{m}$ thick copper $\mathrm{C} 11000$ (hard temper) foil. Although the UAM process made the foils thinner by about $5 \%$, and the grain size reduced from up to $25 \mu \mathrm{m}$ to a more even and finer size of between 0.3 and $10 \mu \mathrm{m}$, it was surprised to see that the average hardness of the foil reduced from around $107 \mathrm{Hv}$ to around 83 Hv. Sriraman et al. [14] believed that this softening effect was caused by dynamic recovery and dynamic recrystallization (DRX). It could be argued that the copper could be annealed during the welding process and such that a reduced hardness. However, the annealing temperature of copper is between 371 and $649^{\circ} \mathrm{C}$, but based on the data published in [65], the maximum process temperature is only $440 \mathrm{~K}\left(167^{\circ} \mathrm{C}\right)$, which is not high enough to anneal the material, so annealing was not the cause of softening in this case. Sojiphan [66] studied the influence of process parameter of VHP UAM on the hardness of Al $3003 \mathrm{H} 18$ foil during UAM fabrication. The results showed that vibration amplitude has significant effect on softening of VHPUAM microstructure of VHP-UAM build. The bulk of samples processed with $28 \mu \mathrm{m}$ vibration amplitude had slightly lower hardness $(69 \mathrm{Hv})$ than the original foil $(70.5 \mathrm{Hv})$, whereas the bulk of samples processed with $38 \mu \mathrm{m}$ vibration amplitude had much lower hardness $(54-57 \mathrm{Hv})$.

In order to understand why sometimes ultrasonic welding has hardening effect and some other time softening effect, some explanation is required. It is believed that this is related to the material used, the temper of the material and the level of the ultrasonic power used. For a material in annealed state, during UAM, if the power is high enough, the material will be severely deformed and dynamic-recrystallised with refined grains. In this case, the material will be hardened after the deposition. This hardening effect had been reported in [64]. For a material in hard or partial hard temper, during UAM, if the power is high enough, the material will be severe deformed and dynamicrecrystallised. Dynamic recrystallization will consume the strained grains to grow new strain-free grains, which will reduce the strength and hardness of the material. In this case, the material could be softened due to dynamic recrystallization. 
This softening effect had been reported by Sriraman et al. [14] on copper C11000 (hard temper), Sriraman et al. [59] on Al 6061 H18 and C11000 (hard temper) and Sojiphan [66] and Sojiphan et al. [67] on Al 3003 H18. In order to have a high ultrasonic power and more softening effect, Sojiphan [66] pointed out that a high oscillation amplitude was much more important than a high normal force. However, for a hard material or a material in hard or partial hard temper, during an ultrasonic welding, if the power is not high enough, then the material will only be slightly work-hardened. In this case, the structure and hardness of the material will not have significant change, as reported in [64] on Al $3003 \mathrm{H} 18$. We should not confuse the ultrasonic irradiation softening effect, the ultrasonic hardening effect and the ultrasonic softening effect. The ultrasonic irradiation softening effect is caused by the acoustic heating and ultrasonic dislocation activation when an ultrasonic irradiation is on the material, as reported by Langenecker [63]; this softening effect will disappear immediately after the ultrasonic irradiation is turned off. The ultrasonic hardening effect is caused by the large plastic deformation introduced at the welding interface and grain refinement. The ultrasonic softening effect is normally related to hard tempered material joined by high power ultrasonic welding systems and it is caused by severe plastic deformation and dynamic recovery and dynamic recrystallization.

Although UAM process sometimes causes work hardening and sometimes causes softening, it always has a grain refinement effect at the welding interface. Li and Soar [64] studied the plastic flow and work hardening of Al alloy matrices during UC/UAM fibre embedding process. They used nano-indentation to study the influence of UC process on foil hardness and used FIB SEM to analyse the gain and sub-grain size. They found grain and sub-grain refinement at the welding interface, especially at the areas close to the embedded fibres, as shown in Fig. 8. Research from Johnson [44] also reported the grain refinement around the welding interface for Al $3003 \mathrm{O}$ parts fabricated by ultrasonic consolidation. Johnson et al. [68] demonstrated that the level of subgrain refinement in ultrasonically consolidated components was seen to decrease as the distance from the weld interface increased.

The grain refinement happens not only at the welding interface but also at the sonotrode-foil interface, and it has been proved that the influence of the interaction between the sontrode and the foil on the grain refinement surpasses that of the interaction between the foils at the welding interface. Shimizu et al. [43] showed that the microstructure close to the top surface of the as-deposited foil due to the interaction with the sonotrode during the deposition could play a key role in the welding of the subsequent foil and its microstructural evolution at the interface. Figure 9 shows the IPF map and the corresponding $\{111\}$ pole figures of an as-deposited foil. The results showed that the bulk material at the bottom of the image had similar microstructure as the as-received Al 6061
Fig. 8 FIB images of the original Al $3003 \mathrm{O}$ foil and the $\mathrm{Al} 3003 \mathrm{O}$ matrix in $\mathrm{SiC}$ fibres embedded samples in different regions: a original foil, $\mathbf{b}$ with right edge less than $1 \mu \mathrm{m}$ away from $\mathrm{SiC}$ fibre, $\mathrm{c}$ with bottom edge less than $1 \mu \mathrm{m}$ away from $\mathrm{SiC}$ fibre and $\mathbf{d}$ with top edge more than $55 \mu \mathrm{m}$ away from fibre [64] a
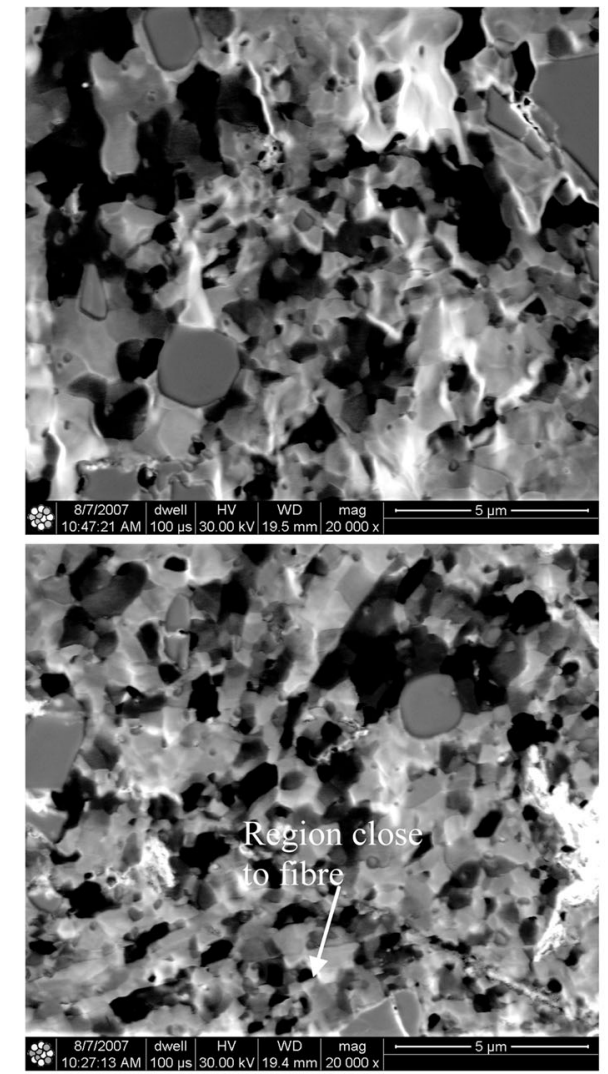

b
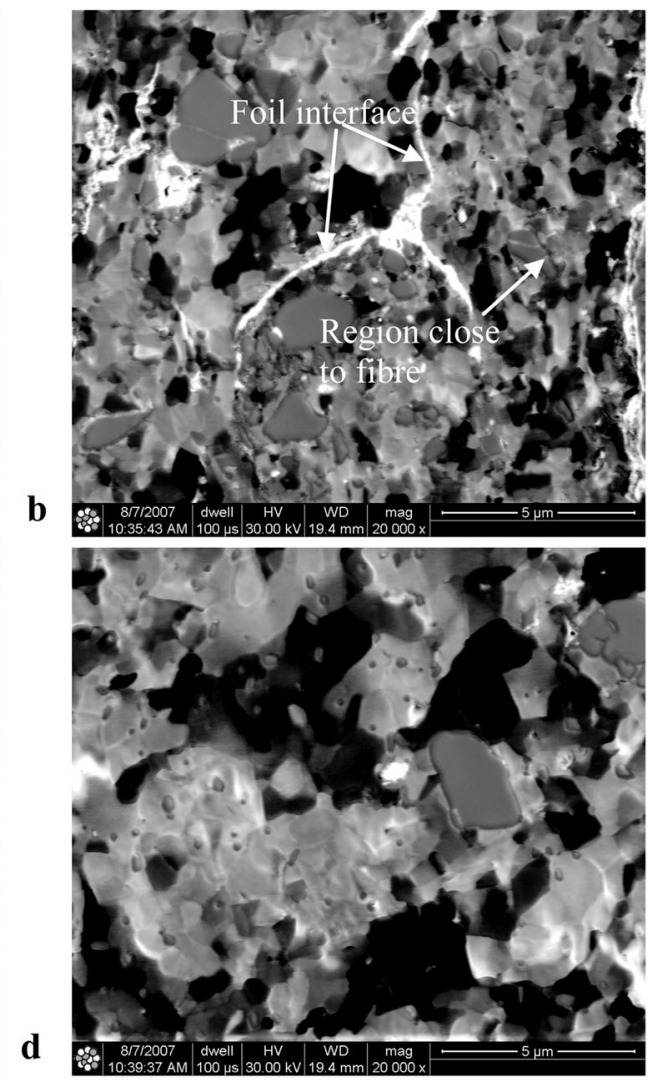
Fig. 9 (left) IPF map around the surface of top layer and (right) corresponding $\{111\}$ pole figures of $\mathbf{A}$ the top-surface region and $\mathbf{B}$ the bottom-surface region [43]

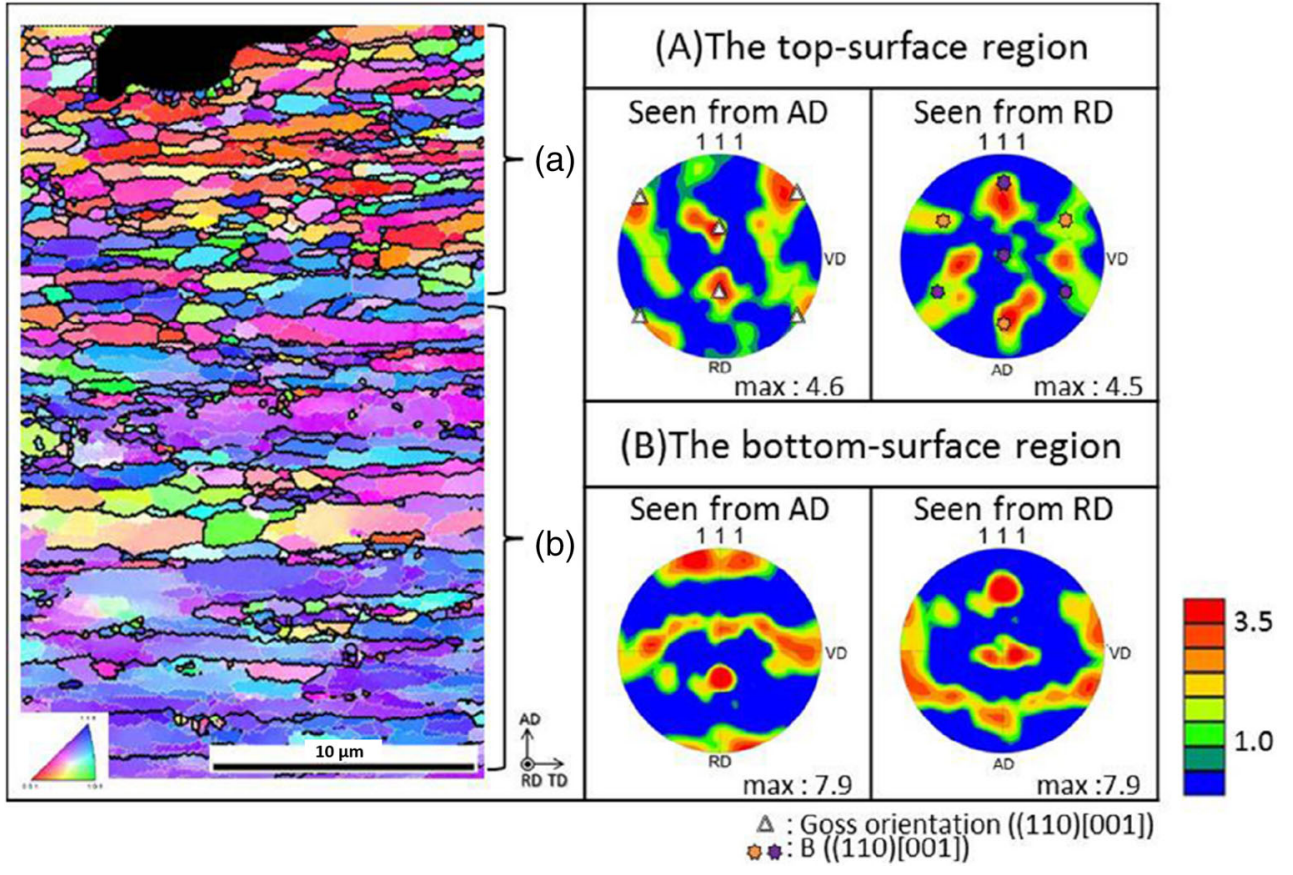

H18 foil and a typical rolling texture; however, at the area next to the top surface of the foil, the grain size became smaller, and the texture of the grains changed to a mixed of recrystallization and shearing texture. It was believed that during UAM process, because the interaction between the sonotrode and the top surface of the foil, the top surface was heated and severely deformed in compression and shear, and this stored energy led to an early stage recrystallization and grain refinement at the top surface of the as-deposited foil. This early recrystallization and grain refinement is the first contribution to the microstructure and texture evolution at the welding interface. Grain refinement from the sonotrode had also been reported by Kuo et al. [18] on the top of 4130 steel foil and by Johnson et al. [68] on the top of Al $3003 \mathrm{O}$. Study from Dehoff and Babu [56] showed that the interaction between the sonotrode and the top surface of the foil during UAM process was very important for the following UAM process from two aspects. First, the sonotrode would produce/transfer some surface texture into the top surface of the foil, which would be very important for the friction and shear plastic deformation during the following deposition. Second, the sonotrode would cause a large shear deformation on the top surface of the foil, leading to early recrystallization and grain refinement.

When another layer of foil is deposited on the top of the previous one, due to the friction at the foil-foil interface, pressure and ultrasonic oscillation applied, the microstructure and texture at the welding interface will evolve further. Figure 10 shows the IPF map around an interface void and the associated $\{111\}$ pole figure of the bottom foil next to the top surface around the void, of an $\mathrm{Al} 6061 \mathrm{H} 18$ parts fabricated by VHP UAM. Comparing the microstructure and the texture of the material in the bottom foil next to the top surface around the void to those of the material next to the top surface of the asdeposited foil in Fig. 9, it can be seen that the grains became smaller and the texture evolved as well. Shimizu et al. [43] pointed out that the microstructure change during this stage is different for the material at the bottom of the void and the material at the bonding interface. For the material at the bottom of the void, further recrystallization is only pushed by additional heating from the UAM process; however, for the material at the interface, further recrystallization is caused by further compression and shear plastic deformation and heating. A number of researches $[43,44,62,66]$ have showed that at the welding interface, the microstructure and texture change are mainly at the top surface of the bottom layer. Although there is some change at the bottom surface of the top layer, the thickness of this region is much smaller than that at the top surface of the bottom layer. It is generally believed that the plastic deformation induced by the sonotrode at the top surface of the top foil is much deeper and more severe than that at the foil-foil interface. Since the top surface of the last deposited layer will be the top surface of the bottom layer when a second layer is deposited on the top, due to the accumulated effect of the early stage recrystallization and grain refinement induced by the sonotrode as explained above, the recrystallization and grain refinement zone on the top surface of the bottom layer will be much thicker than that on the bottom surface of the top layer. Similar results were presented by Johnson [44]. His results demonstrated that nano-grains formed by grain refinement mainly caused by sonotrode-foil interaction, although a smaller amount of nano-grains formed through foil-foil interaction. 
Fig. 10 a IPF map around an interface void, $\mathbf{b}$ the associated $\{111\}$ pole figure of the bottom foil next to the top surface around the void. Modified from [43]

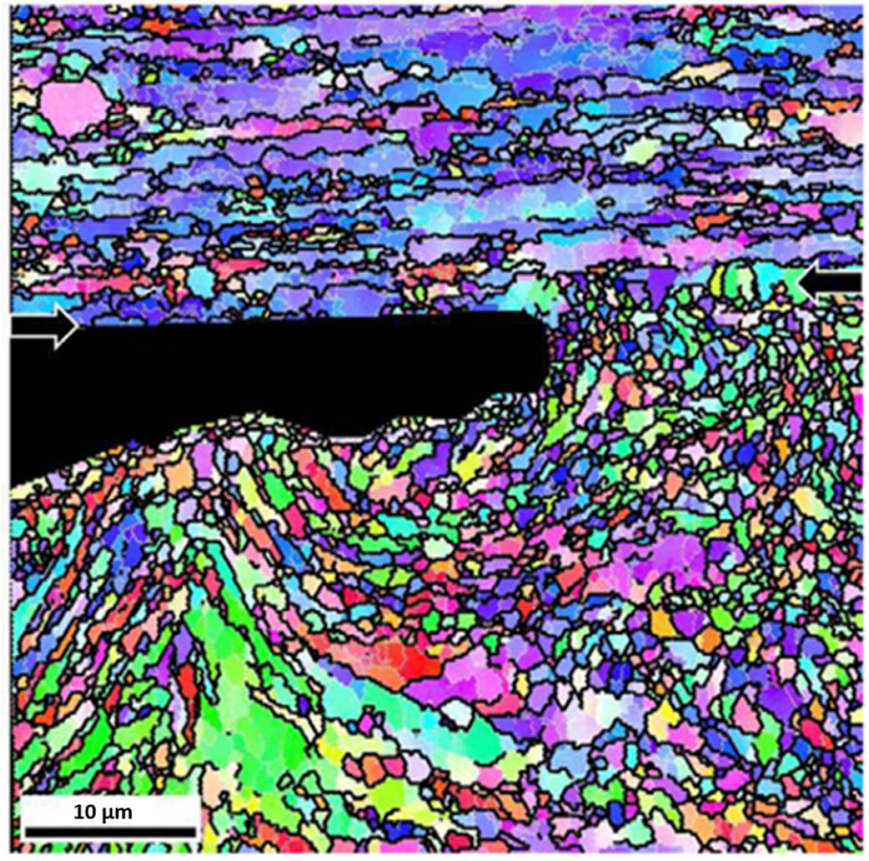

(a)
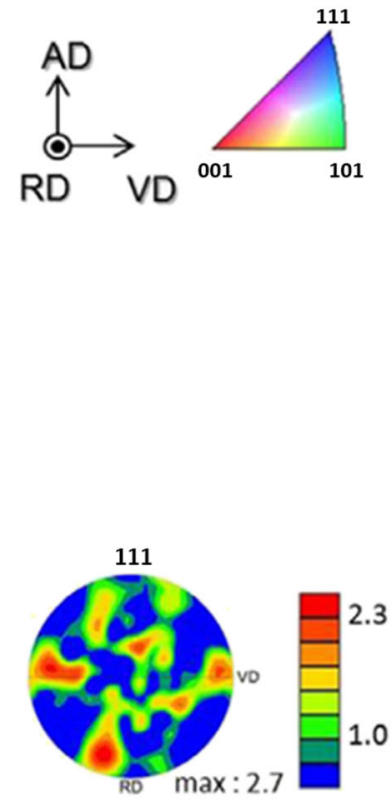

(b)
When UAM is used to build a part with multi-layer of foils built on the top of the others, the microstructure and texture at the interfaces will have some general features like those describe above, and there will be some difference at different interfaces due to the accumulative effect when more and more foils are deposited on the top. Figure 11 shows a set of inverse pole figure (IPF) maps in Al $3003 \mathrm{H} 18$ fabricated by VHP UAM (amplitude $=26 \mu \mathrm{m}$, normal load $=5.6 \mathrm{kN}$ and speed $=$ $35.6 \mathrm{~mm} / \mathrm{s}$ ). The data are obtained from different positions within the step-like build. These locations are also schematically annotated in Fig. 11. The grain boundaries are shown by black lines, and the grain orientations can be inferred from the colour scale in the IPF. The approximate location of the interface between aluminium foils is represented by the whitecoloured arrows. As seen in every map, there is a clear microstructural difference between the interface and bulk regions. Many grains in the bulk region, which is far from the interface, are elongated along the rolling plane of the original foil, and fine grains are seen between the elongated grains. The length of the major axis of the elongated grains is greater than $10 \mu \mathrm{m}$, and the size of fine grains is about $1 \mu \mathrm{m}$. On the other hand, all grains close to the interface are fine and equiaxed. The microstructure can be divided into three regions (top region, interface region and bottom region) and illustrated in Fig. 11e. The interface or the bond regions are discriminated only based on the grain structure between them and the bulk. The thickness of the interface region is approximately 10 to $20 \mu \mathrm{m}$. These equiaxed regions appear to be on the lower side of the $(n+1)^{\text {th }}$ and $n^{\text {th }}$ foil interface. This region corresponds to the top surface of $n^{\text {th }}$ foil during the VHP UAM process. The average grain size in the interface region was smaller than that in the bulk region, whilst the maximum grain size in the interface region, on the other hand, was much smaller than that in the bulk region. The data revealed that the interfacial deformation associated with ultrasonic oscillation led to finer average grain size and homogeneous microstructure. It can also be seen that the extent of recrystallized grains in the bottom bulk region was greater than that of the top bulk region, and overall, the degree of grain refinement in the lower bonding interface was greater than that in the upper bonding interface. Similar results had been confirmed in Al 6061 H18 parts by Shimizu et al. [43].

With the increase of building height, it is believed that there is some accumulative effect on the bottom layers deposited first due to the cyclic heating effect during the following deposition process. When studying the microstructure evolution of VHP UAM-fabricated Al 3003 H18 parts, Fujii et al. [62] showed that the recrystallized regions expanded and some grain growth occurred in the interface region subjected to accumulative effects, as shown in Fig. 11a and d.

With an increase in build height, the stiffness of the part along the height direction will reduce, and the whole part will have a higher bending deformation along the sonotrode vibration direction. As a result, the effective shear deformation at the welding interface will be reduced, the driving force/stored energy for recrystallization will be smaller, recrystallization and gain refinement zone will be smaller and the degree of grain refinement will be lower. This has been proved by the research from Sojiphan [66], in which they confirmed that with the same process parameters, the required power was 

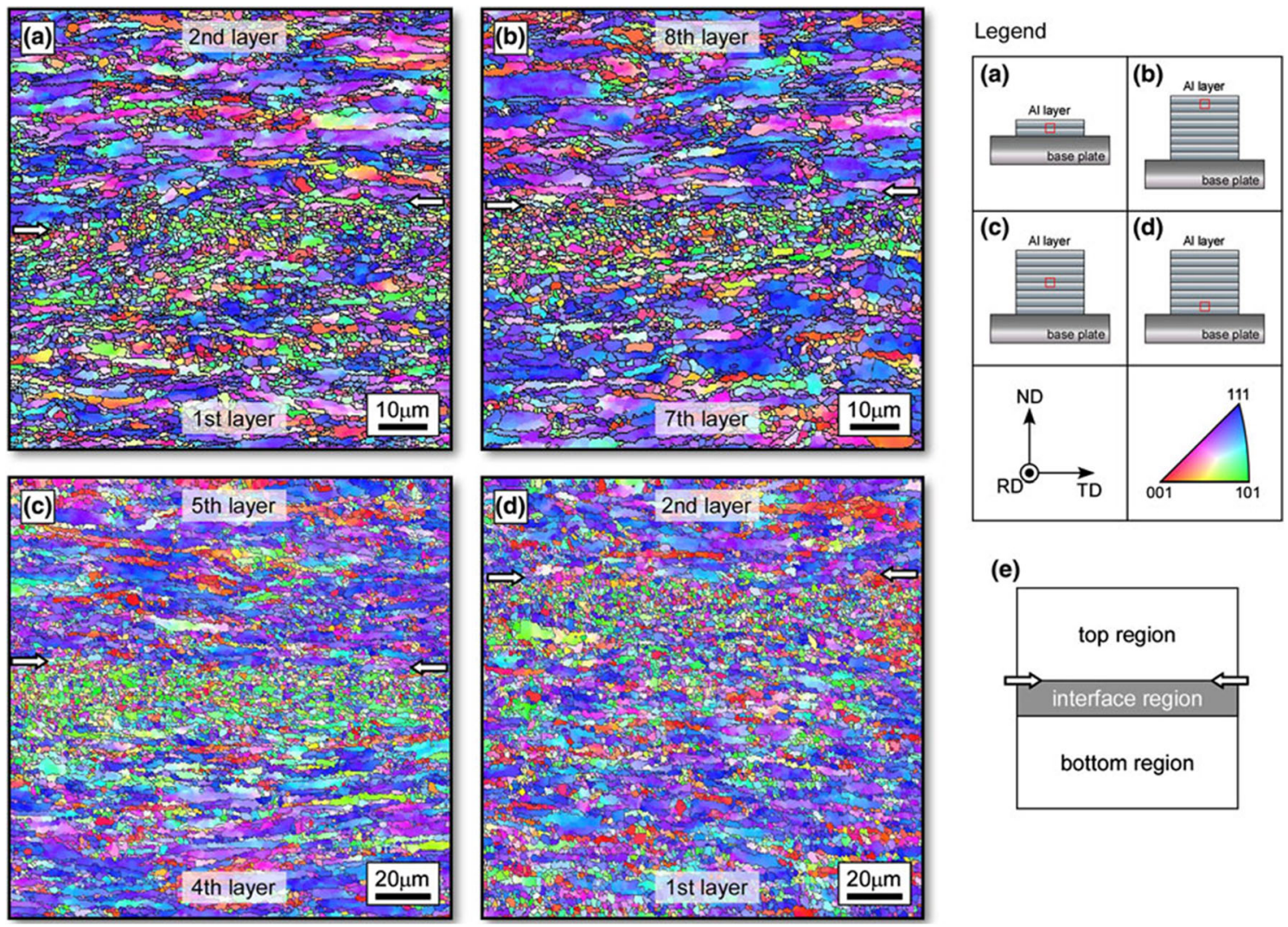

(e)

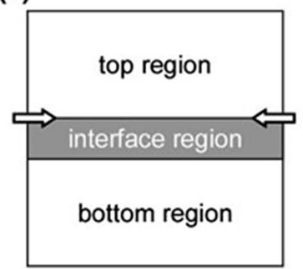

Fig. 11 IPF maps around the interface between the a first and second foils of sample A, b seventh and eighth foils, $\mathbf{c}$ fourth and fifth foils and $\mathbf{d}$ first and second foils of sample B in VHP-UAM Al 3003 alloy. In the analysed area in each specimen, the sample coordinate system and the colour correspondence scale are shown in the legend. $\mathbf{e}$ The definition of the regions divided by the microstructure [62] lower when the build height was increased. It was also confirmed by Schick [69] by the reduced measured temperature with the increase of build height. It was further confirmed by Fujii et al. [62] from the IPF maps obtained at the different regions, as shown in Fig. 11. The microstructural differences between the first and second layers (Fig. 11a), as well as the seventh and eighth layers (Fig. 11b), were analysed. Since both interfaces experienced only one cycle of the VHP UAM process, the accumulative effects on microstructure were not expected, and if similar shear deformation occurred, similar microstructures would be expected. However, from Figs. 11a and b, it can be seen that with the increased building height the degree of dynamic recrystallization and grain refinement reduced, with Fig. 11a showing a thicker recrystallization and grain refinement zone. The stored energy for recrystallization and grain refinement is mainly from the shear deformation at the interface, so this proved that with the increase of build height, the extent of deformation (strains) at the interfaces decreased.

As mentioned before, soft materials like $\mathrm{Al}$ are easy to be bonded by UAM; for harder materials, such as $\mathrm{Cu}, \mathrm{Ni}$, steel and $\mathrm{Ti}$, more power is required, or there will be less plastic deformation at the interface. Sriraman et al. [14] studied the bonding characteristics during fabrication of $\mathrm{Cu}$ parts by VHP UAM. The process parameters of $36 \mu \mathrm{m}$ amplitude, $6.7 \mathrm{kN}$ normal force and $30 \mathrm{~mm} / \mathrm{s}$ travel speed were used. Their results showed grain refinement at the welding interface, as shown in Fig. 12, but it can also be seen that the grain refinement was not even at the interface, with some areas, the grains were much smaller. Yang et al. [16] studied the microstructures of Ni-Ni weld interface by UAM. Annealed $75 \mu \mathrm{m}$ thick Ni 201 alloy was used. The process parameters that they used are as follows: oscillation amplitude, $16 \mu \mathrm{m}$; welding speed, $28 \mathrm{~mm} / \mathrm{s}$ and normal force, $1.75 \mathrm{kN}$. Their results showed that for normal well-bonded interface, the grains at the weld interface did not have much difference with those in the bulk material, as shown in Fig. 13a, which means no obvious grain refinement at the interface. However, they also found out that in some weld interface locations with voids, there were a thin layer of very fine grains on the foil surfaces, as shown in Fig. 13b. Yang and co-workers could not explain this phenomena at the time, but I believe that this could be caused by very large plastic deformation: These local areas were bonded by ultrasonic welding during early stage of the welding and fine grains grew at the bonding interface; however, they were torn apart during later stage due to the large amount of plastic 


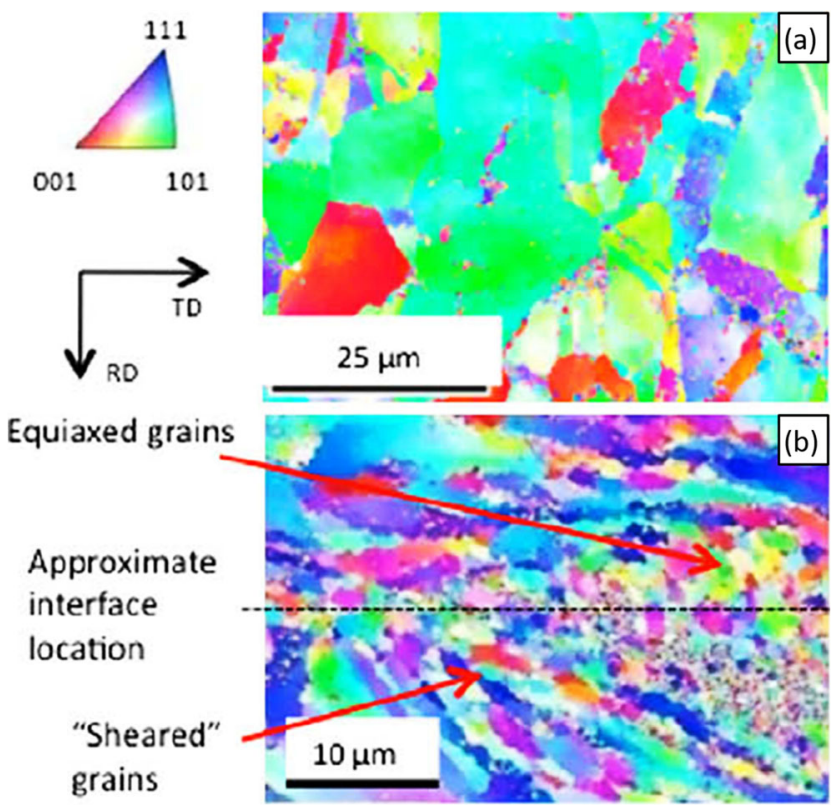

Fig. 12 a Inverse pole figures of the as-received $\mathrm{C} 11000 \mathrm{Cu}$ tape and $\mathbf{b}$ an interface region of the $\mathrm{C} 11000 \mathrm{Cu}$ build sample [14]

deformation and local stress introduced by the high level of ultrasonic oscillations and high degree of shear movement between the top and the bottom foils.

When a soft material is bonded to a hard material, normally, the main plastic deformation and grain refinement happen only on the soft material side. It is believed that the bond formation in UAM of dissimilar material primarily relies on severe shear deformation of the soft material at the interface. Wolcott et al. [21] fabricated Al-Ti-interlayered material using VHP UAM. Figure 14 shows the EBSD microstructure of an as-built Ti-Al part. The results show significant deformation in the aluminium layers at the titanium/aluminium interfaces. The aluminium layers have a nominal thickness of $127 \mu \mathrm{m}$ before welding, which is reduced to around
$70 \mu \mathrm{m}$ after the UAM process. By contrast, the titanium layers are nominally $127 \mu \mathrm{m}$ before welding and $125 \mu \mathrm{m}$ after welding. The layers lower in the build show more grain refinement and deformation than layers further up the build (accumulated effect). Compared with the grain structure of the titanium foil before welding, it appears that the microstructure in the titanium is unchanged during the welding process, with all deformation and refinement occurring in the soft aluminium layers. Similar results were reported by Sridharan et al. [19] when studied the microstructure and texture of AlTi parts built by UAM. Their results showed that during the ultrasonic welding process grain-refining and grain misorientation happened on the $\mathrm{Al} 1100$ layers, but not on the Ti layers. Sridharan et al. [22] also reported when $\mathrm{Al} 6061$ and 4130 steel were bonded together using UAM, grain refinement only happened on the Al side, as shown in Fig. 15.

During UAM process, the texture of the material at the welding interface gradually changes from rolling texture to shear texture [62]. Figure 16 shows the $\{111\}$ pole figures of Al 3003 H18 parts fabricated by VHP UAM, which were extracted using the data from the top, interface and bottom regions, as shown in Fig. 11. It can be seen that a typical rolling texture was observed in the top and bottom bulk regions of every specimen, but at the welding interface, the texture was mainly shear texture and recrystallization texture [62]. Similar results were reported by the same group on $\mathrm{Al}$ $6061 \mathrm{H} 18$ parts fabricated by VHP UAM [43].

Sojiphan [66] also studied the texture at the Al 3003 H18 bonding interface after VHP UAM process, based on EBSD analysis and neutron diffraction. Similarly, they found the texture at the bonding interface changed from rolling texture to shear texture. They also demonstrated that larger oscillation amplitude would introduce larger shear deformation and increase the portion of shear texture. They proved that there was an accumulative thermomechanical effect on the bulk of the
Fig. 13 An inverse pole figures of $\mathrm{Ni}-\mathrm{Ni}$ UAM welding interface, a a well-bonded interface (the line across the centre of the image defines the Ni-Ni weld interface.), $\mathbf{b}$ an interface with a void [16]

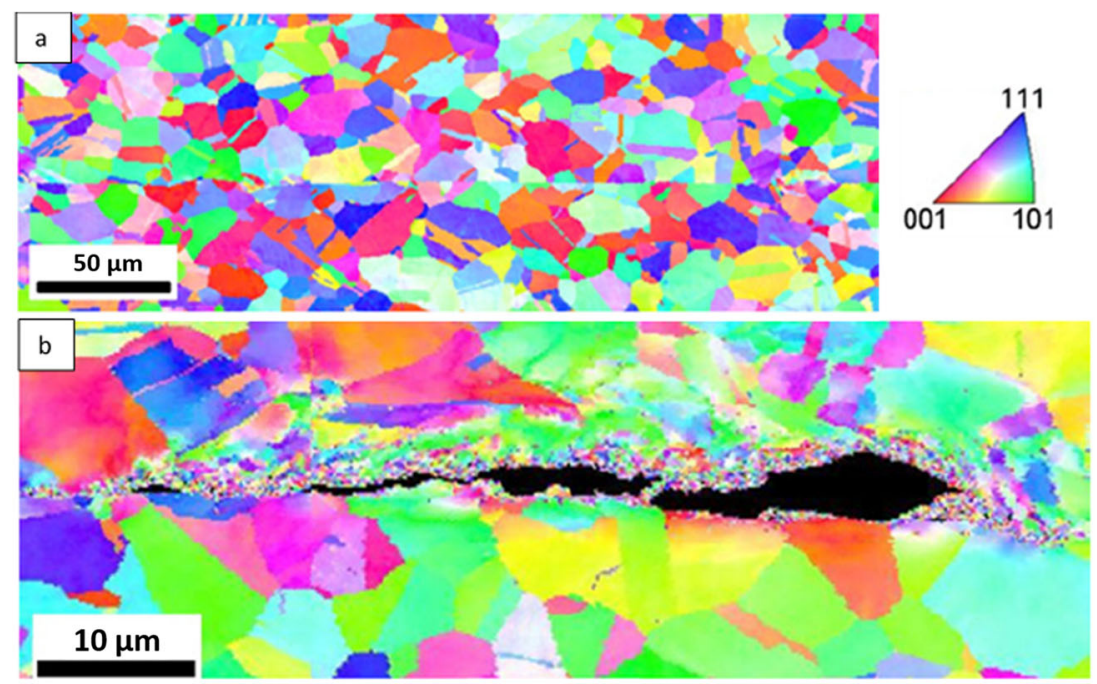




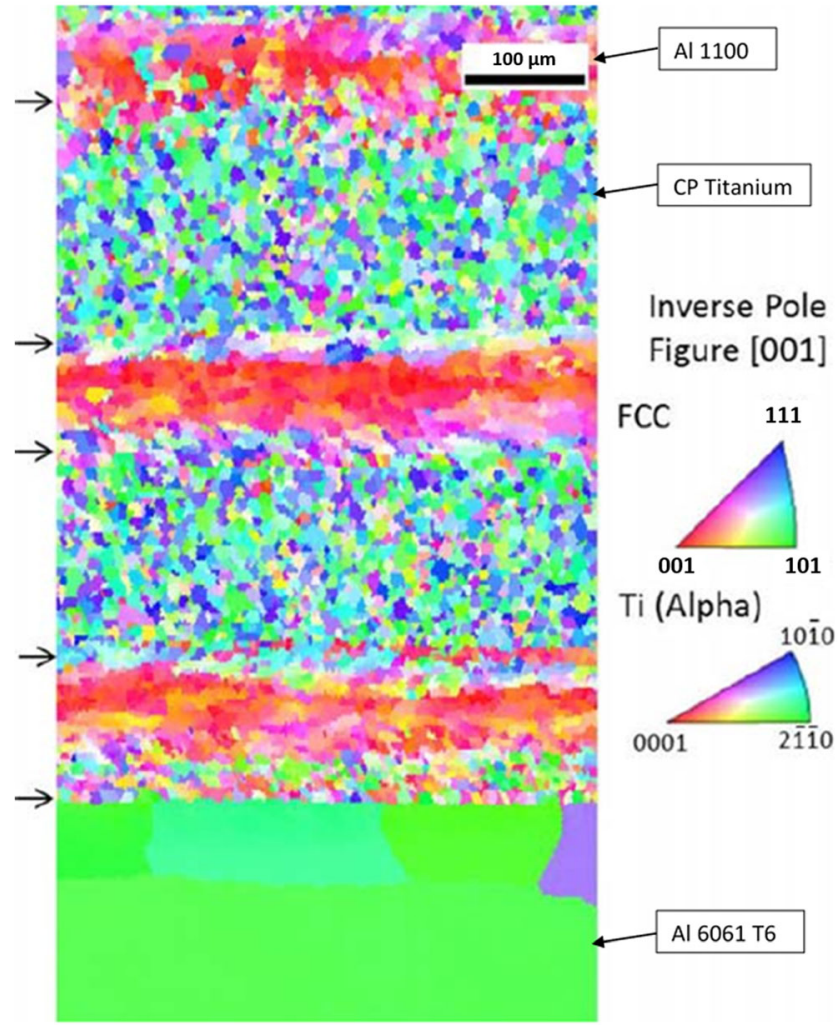

Fig. 14 Electron backscatter diffraction image of Ti-Al joint; arrows indicate approximate location of material interfaces [21]

VHP UAM-fabricated parts, because the lower layers of the build demonstrate higher fraction of shear texture, and lower fraction of certain rolling texture components. This texture change has also been reported for other material combinations fabricated by UAM [15, 19, 55].

It is believed that the microstructure and texture change at the UAM bonding interface happen at three different stages: (1) due to the interaction between the sonotrode and the top surface of the foil, such as heating, compression and shear deformation, when it is first deposited and if the top layer is not machined off before a following deposition; (2) due to the interaction between the top and the bottom foils, such as heating, compression, shear deformation and inter-diffusion, when a second foil is deposited on the top and (3) due to the following thermomechanical cycling, when further foils are deposited on the top.

\section{Influence of heat-treatment on microstructures}

Mechanical properties of the UAM-fabricated parts mainly depend on the characteristics of the interface region between the layers; thus, achieving continuous and strong interfacial bonding is necessary. However, currently, the UAM process does not always result in robust and repeatable joining of metallic foils, especially for some hard materials. Because the UAM process operates at temperatures below melting and the heat generated is quickly dissipated, intermetallics are not generated at the interface [65]. It has been reported that the bulk material properties of ultrasonically consolidated material tested in tension along the building direction exhibit poor strength and ductility [70]. Post-process heat treatments can be performed to improve bonding through controlled generation of intermetallics, which constrain the bond area and increase mechanical strength [52]. Post-process heat treatment can also relax residual stress and promote inter-diffusion and controlled intermetallics growth, which are beneficial for mechanical strength as well.

Wolcott et al. [21] studied the influence of heat treatment on the microstructures of the UAM-fabricated Al-Tiinterlayered material. Heat treatment was performed in a conventional induction furnace in an air atmosphere at $600^{\circ} \mathrm{C}$ for $1 \mathrm{~h}$. After the heat treatment, the grain structure in the titanium layers appears unchanged compared to the as-built samples, whilst the aluminium layers show significant grain growth, as shown in Fig. 17. In each of the aluminium layers, it appears the heat treatment has caused preferential grain growth into

Fig. 15 a Inverse pole figure map of the Al-6061 substrate. Note the grain sizes; $\mathbf{b}$ inverse pole figure map showing the interface. Note the refinement of grains in the $\mathrm{Al}$ interface; $\mathbf{c}$ grain boundary positions overlaid on a phase map where green represents Al-6061 substrate and the red represents the steel foil [22]
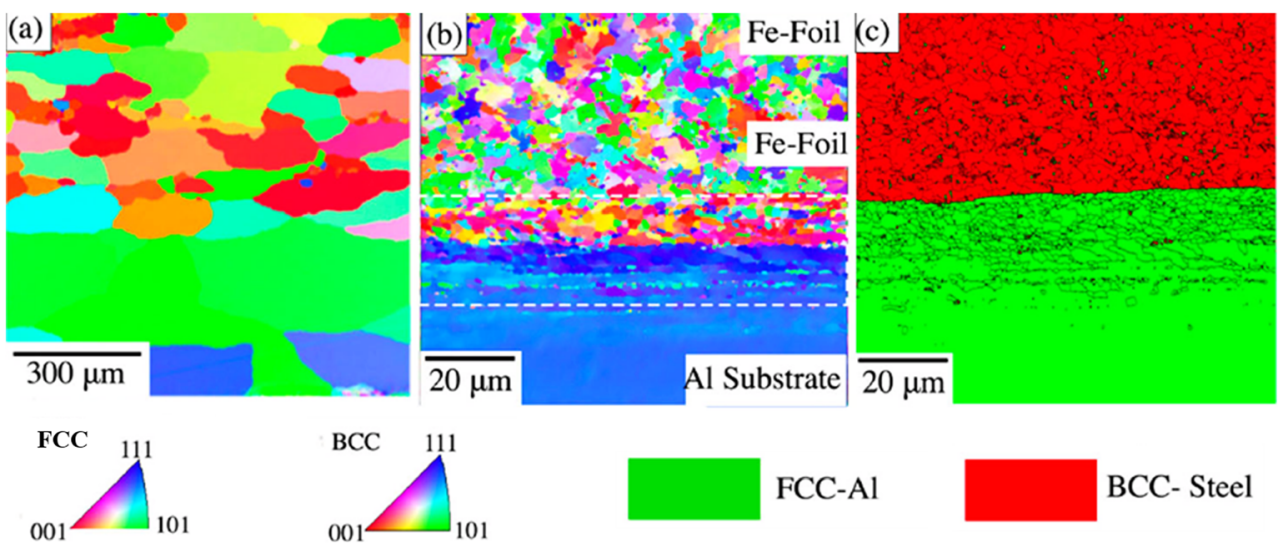

FCC-Al 


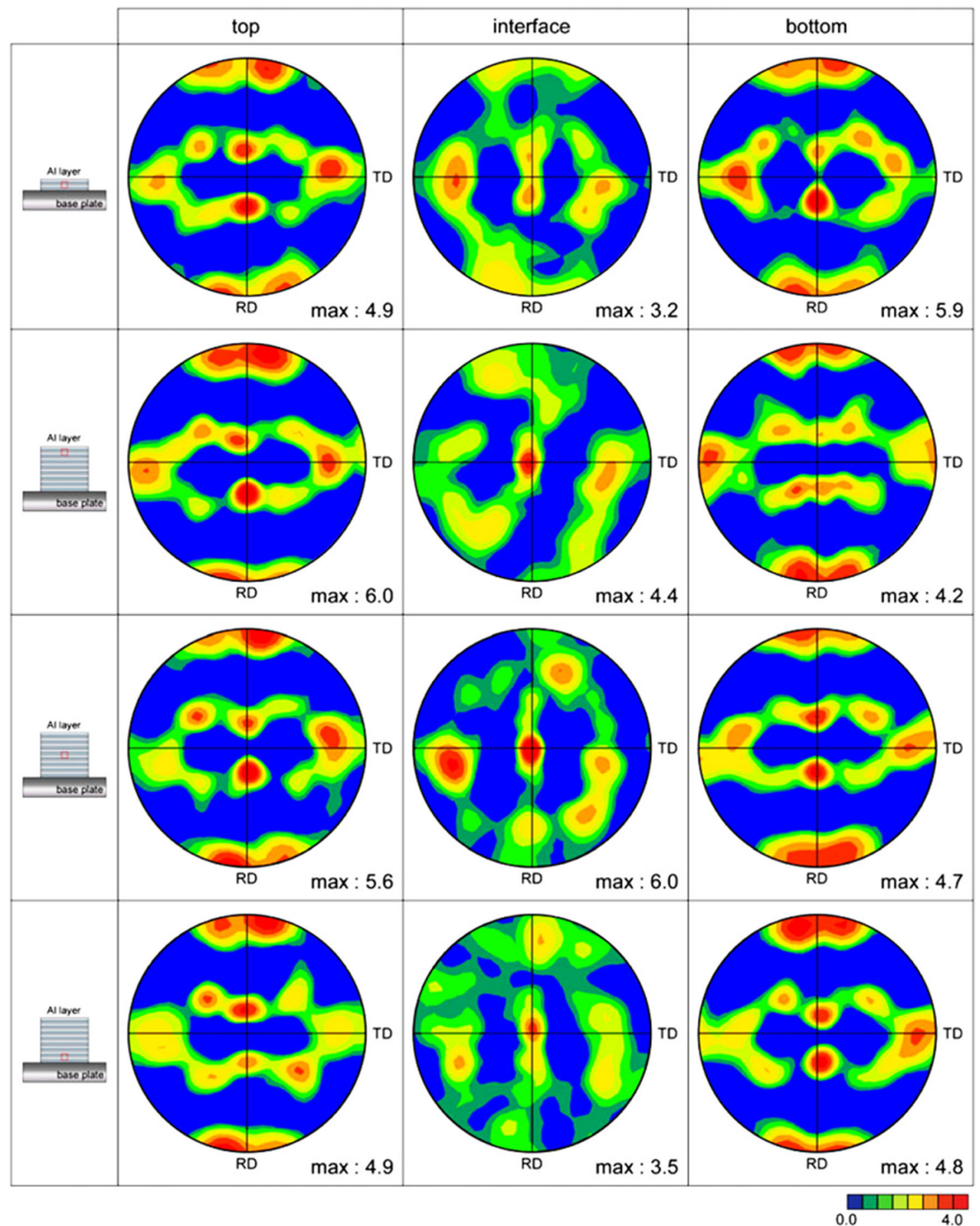

Fig. 16 The $\{111\}$ pole figures derived from each area of the maps in Fig. 11; left column shows top bulk region, middle column shows interface region and right column shows bottom bulk region. The colour intensity scale is shown in the bottom right corner [62]

only a few stress-free grains for each layer. It was believed that this different grain growth was related to the plastic deformation during the deposition process. Al layers had large plastic deformation during the deposition and stored high energy in the grains, so during heat-treatment, they had more driving force for recrystallization. On the other side, Ti layers had little plastic deformation and stored little energy in the grains, and such that low driving force for recrystallization during heat treatment. The different melting temperatures between $\mathrm{Al}$ and Ti was another reason for this grain growth difference. The heat treatment temperature of $600{ }^{\circ} \mathrm{C}$ is very close to the melting temperature of $\mathrm{Al}$ (around $660^{\circ} \mathrm{C}$ ) but very far away 


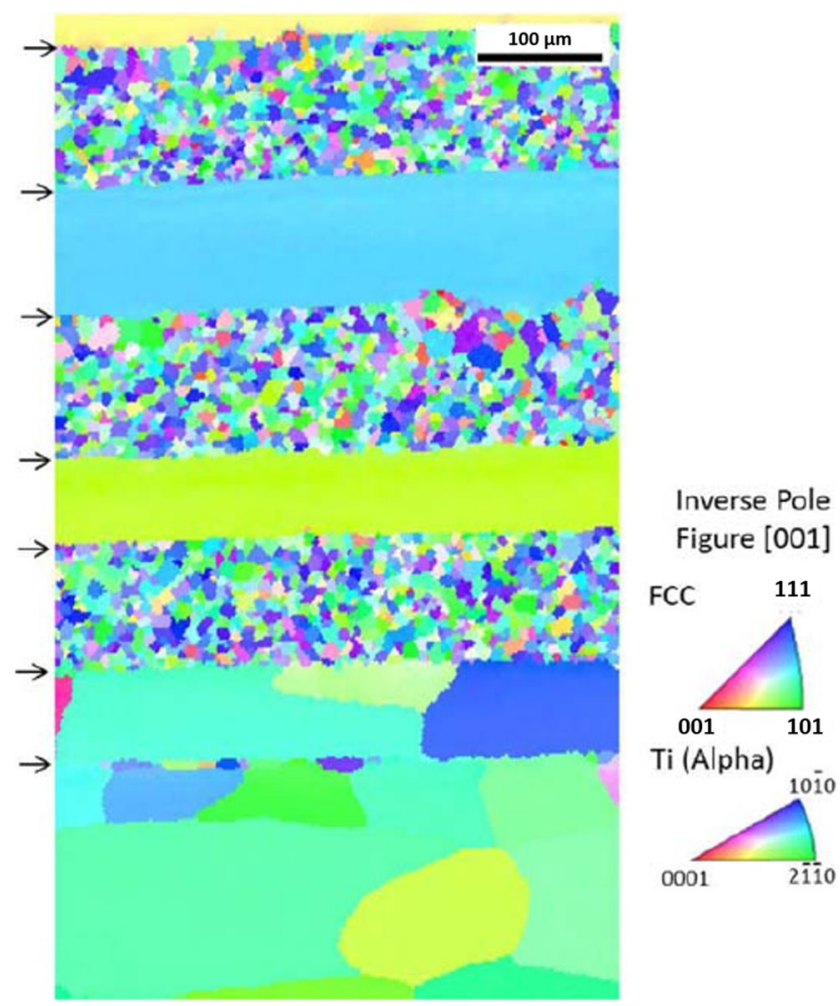

Fig. 17 Electron backscatter diffraction image of Ti-Al joint after heat treatment; arrows indicate approximate location of material interfaces [21]

from the melting temperature of $\mathrm{Ti}$ (around $1668^{\circ} \mathrm{C}$ ). Grain growth happened in the substrate Al 6061 material as well, though not to the extent of the growth in Al 1100 layers.

Although excessive intermetallics at the joint interface is detrimental for joint strength due to the generally brittle feature of intermetallics, a thin layer of intermetallics can increase the interface bonding strength and joint strength between dissimilar materials, just like brazing. The results from Wolcott et al. [21] showed that heat-treatment increased the diffusion zone between the $\mathrm{Al}$ and Ti layer from 1 to $5 \mu \mathrm{m}$. Due to this structure change, the shear strength of the heat-treated samples increased from 46.3 $\mathrm{MPa}$ of the as-built samples to 102.4 $\mathrm{MPa}$. Also after the heat treatment, the push-pin strength increased from 3.5 to $12.7 \mathrm{kN} \mathrm{mm}$. The specimens before and after heat treatment also showed different failure modes. Heattreated specimens failed through multiple layers, whilst asbuilt samples failed mostly by delamination of a single layer. Truog [52] studied the influence of heat treatment on the mechanical strength of Al-Cu parts fabricated by VHP UAM. The heat treatment was done at $350{ }^{\circ} \mathrm{C}$ for $10 \mathrm{~min}$. The results showed that heat treatment could increase the push-pin joint strength between 20 and $40 \%$, and heat treatment also increased the failure energy and maximum deformation. There were three different $\mathrm{Al}-\mathrm{Cu}$ intermetallics that grew at the interface during the heat treatment, which was the key reason for the joint strength increase. Kuo et al. [18] used post-weld heat treatment to increase the strength of 4130 steel parts with $\mathrm{Ni}$ as an interlayer fabricated by UAM. The heat treatment was conducted at $1000 \mathrm{~K}$ for 1 to $10 \mathrm{~h}$. The inter-diffusion zone between steel and Ni could grow up to $10 \mu \mathrm{m}$, and the joint shear maximum load was increased from 1.59 to $6.5 \mathrm{kN}$ after $10-\mathrm{h}$ heat treatment.

Similarly, Obielodan [26] studied the influence of postprocess heat treatment on the shear strength of ultrasonically consolidated commercially pure titanium and Al 3003 dualmaterial systems. The post-process heat treatment was conducted at $480^{\circ} \mathrm{C}$ for $30,60,120,180$ and $270 \mathrm{~min}$. The results show that the strength of post-processed specimens increased significantly over the as-consolidated ones. The best shear strength increase happened after heat treatment for $30 \mathrm{~min}$, with the average strength increased from 38 to $73 \mathrm{MPa}$. They believed that the improvement was a result of stressrelieving of the strain hardened interface between the two materials and some interactions of the substrate materials across the interfacial boundaries at elevated temperatures. The results also showed that heat treatment for an over-long period, more than $30 \mathrm{~min}$, would cause excessive grain growth and reduce the joint strength.

Wolcott et al. [41] also studied the influence of postprocess heat treatments on the bonding and mechanical properties of Al 6061 UAM builds. Two heat-treatments, annealing and T6, were conducted to the as-built parts. For annealing (O): parts were heated to $413^{\circ} \mathrm{C}$ for $2.5 \mathrm{~h}$, cooled at $1{ }^{\circ} \mathrm{C} / \mathrm{min}$ until $280^{\circ} \mathrm{C}$ and then air-cooled; for T6: parts were heated to $530{ }^{\circ} \mathrm{C}$ for $1 \mathrm{~h}$ to solutionise, then quenched in water and then heated to $160{ }^{\circ} \mathrm{C}$ for $18 \mathrm{~h}$. The results showed that the postprocess heat treatments (T6) increased the bond strength over the as-built conditions, to an out-of-plane tensile strength close to $90 \%$ of bulk material strength.

Study from Schick [69] showed that post-process heat treatment of UAM built Al $3003 \mathrm{H} 18$ parts at $343{ }^{\circ} \mathrm{C}$ for 2 hours resulted in an increase in linear weld density from 62.7 to $80.6 \%$ but a decrease in hardness from 75 to $62 \mathrm{Hv}$. Sojiphan [66] studied the influence of heat treatment on the microstructure and texture of UAM parts. Each sample was heated in the Lindberg Blue Tube furnace in an argon atmosphere at $343{ }^{\circ} \mathrm{C}$ for 2 hours, followed by furnace cooling to room temperature. Their results showed that during heat treatment, all grains in the VHP UAM-fabricated Al $3003 \mathrm{H} 18$ parts grew, as shown in Fig. 18. However, the growth of grains in the bulk foils was much larger than that of grains at the welding interfaces and the grain growth in the bulk foils consumed some grains at the interfaces as well. Sojiphan [66] also found that after heat treatment, the rolling texture from the original $\mathrm{Al} 3003 \mathrm{H} 18$ was reduced and became much weaker; however, the shear textures produced during the UAM process, at the interface region, were very stable without decreasing in its volume fraction.

Apart from heat treatment, other post-process treatments, such as spark plasma sintering (SPS) $[17,21]$ and 
Fig. 18 Inverse pole figure maps of heat-treated Al 3003-H18 VHP-UAM samples across one layer (TB-10-28-5340 means test bed machine (TB) was used, total 10 layers were built and oscillation amplitude of $28 \mu$ and normal force of $5340 \mathrm{~N}$ were used) [66]
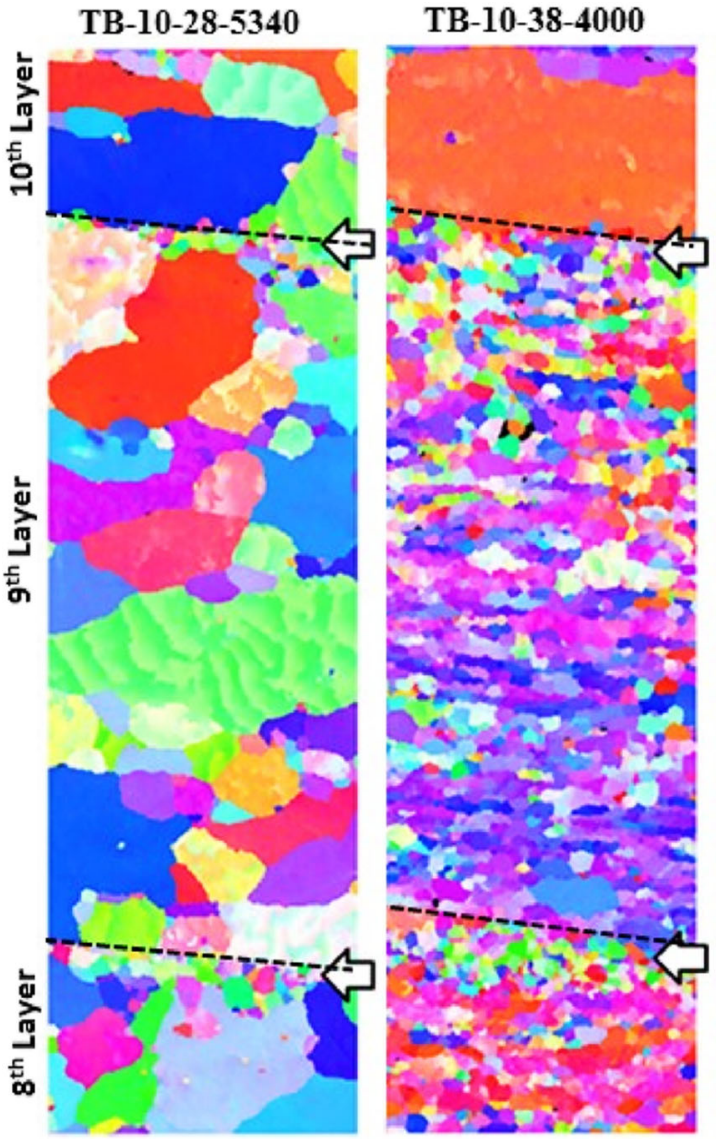

TB-10-38-8000

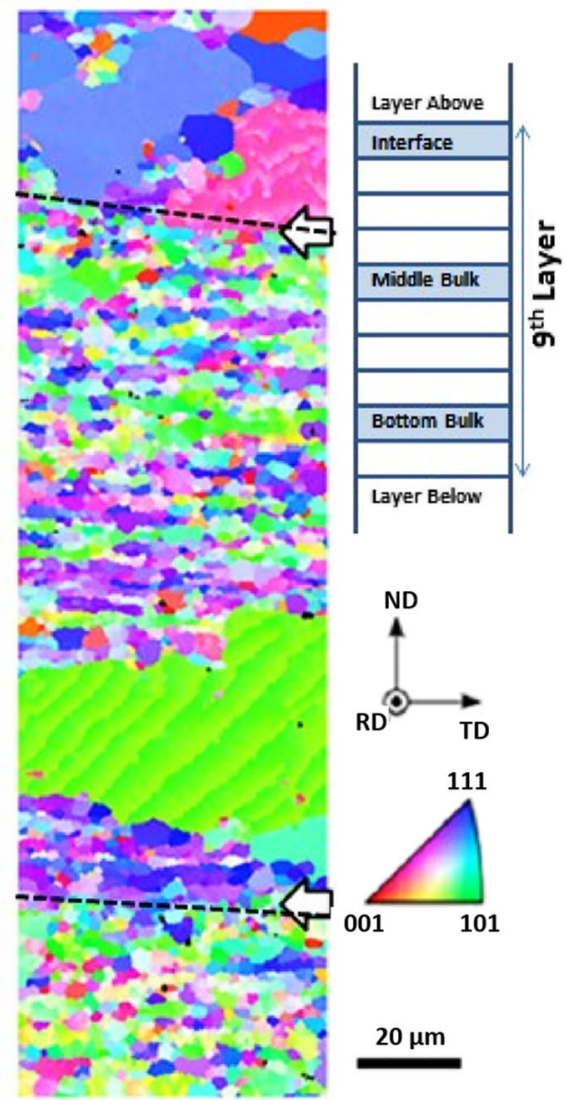

hot isostatic pressing (HIP) [17, 58], were also used and proved to be effective to improve the mechanical properties of UAM built parts.

\section{Summary and future perspectives}

When UAM is used to build parts, due to the compression, friction and shear deformation at the interface, the process changes the microstructure and texture at the welding interface and sometimes even in the bulk materials. There are different factors that affect the void level at the interface, the microstructure and texture evolution, plastic flow and mechanical strength.

It is generally believed that increase of ultrasonic oscillation amplitude, normal force and preheat temperature, and decrease of welding speed will increase the LWD and the mechanical strength of the fabricated parts. However, these parameters need to be limited to a level that will not cause fatigue embrittlement. Certain level of surface roughness is required on the welding interface to ensure a sound bonding. For a high surface roughness, a high ultrasonic energy input is required to ensure that there is enough plastic flow to fill the micro-valleys on the surface to reduce the void level at the interface. Softer materials are easier to be bonded by UAM, and for harder materials, more power will be required to produce enough shear deformation and plastic flow at the interface to increase the LWD. In order to reduce the void level during UAM fabrication, a proper strategy on edge-to-edge overlapping and layer-to-layer overlapping is required.

Due to the compression and cyclic shear plastic deformation, plastic flow happens at the welding interface. The plastic flow is very important for redistribution of oxide layer, forming of mechanical interlocks, filling the voids at the interface and embedding fibres and other elements.

Generally speaking, UAM process will cause recrystallization and grain refinement at the welding interface and the intimate bulk materials around, and it will also gradually change the texture from rolling texture to shear texture. The interaction between the sonotrode and the top surface of a foil when it is first deposited is very important for the following deposition step. The sonotrode will compress the foil and transfer some of its surface texture to the top surface of the foil. In the meantime, the sonotrode will compress, shear and heat the foil to produce a deep shear zone, resulting some early stage recrystallization and grain refinement. When another foil is deposited on the top, the roughened surface on the justdeposited foil will help to increase the friction and shear deformation at the interface, which will cause further recrystallization and grain refinement. The shear zone caused by the 
foil-foil interaction is much shallower, when it is compared with that caused by the sonotrode-foil interaction. Due to the accumulated effect, at the welding interface, the recrystallization and grain refinement zone is mainly at the bottom foil side. When fibres or other objects are embedded into substrates by UAM, level of the grain refinement will be much higher around the fibres or the objects.

Due to the additive manufacturing nature, when more foils are deposited on the top of already deposited layers, there will be accumulative effect due to the thermomechanical cycling applied. It has been observed that the recrystallized regions expanded and some grain growth occurred. With the increase in build height, the stiffness of the part along the height direction will reduce, and the whole part will have a higher bending deformation along the sonotrode vibration direction. As a result, the effective shear deformation at the welding interface will be reduced. With a reduced stored energy, the driving force will be smaller and the recrystallization and grain refinement zone will be smaller and the degree of grain refinement will be lower.

When a soft material is bonded to a hard material by UAM, the compression and shear deformation mainly happen at the soft material side. Consequently, mainly, the grains on the soft material side are refined and the microstructure of the material on the hard material side does not have obvious change.

Some UAM built parts are not very strong due to the existing of voids and weak bond at the interface, especially for tensile strength along the building direction. This is especially true for hard substrate materials, such as $\mathrm{Ni}$, steel and $\mathrm{Ti}$, so post-process heat treatment is required to increase the part strength. Post-process heat treatment normally involves putting the parts in a furnace with certain temperature for certain time (substrate material related) and then cooling down to room temperature, although other treatments, such as SPS and HIP, can also be used. Heat treatment can relax residual stress, promote inter-diffusion and intermetallics growth at the interface, which in turn will increase the part strength. During heat treatment, there will be grain growth and texture evolution. It has been found that the fraction of the rolling texture in the bulk foils will be gradually reduced; however, the shear texture produced during the UAM process is stable during the heat treatment. For UAM build with dissimilar materials, during heat treatment, grain growth only occurs on the compression and shear deformed soft material.

Based on the current research on UAM, the future research should be focused on the following: (1) further understanding of UAM mechanisms, including indirect deposition mechanism and multi-layer deposition mechanism; (2) further research to increase the bonding density and joint quality of hard materials, such as steel, Ti alloys and Ni alloys; (3) improve the joint quality and ability of embedding active elements, such as fibre optical sensors, printed circuit boards and other sensors and (4) simulation of UAM in micro- and macro-scale for residual stress, part strength and microstructure.

Acknowledgements The authors would like to thanks the support from Innovate UK through High Value Manufacturing Catapult.

Author's contributions Dezhi Li is the sole author of this paper.

Funding This study was funded by Innovate UK through High Value Manufacturing Catapult.

Data availability Data sharing is not applicable to this article as no new data were created in this study.

\section{Compliance with ethical standards}

Conflict of interest The author declares there is no conflict of interest.

Code availability Code sharing is not applicable to this article as no new code was created in this study.

Open Access This article is licensed under a Creative Commons Attribution 4.0 International License, which permits use, sharing, adaptation, distribution and reproduction in any medium or format, as long as you give appropriate credit to the original author(s) and the source, provide a link to the Creative Commons licence, and indicate if changes were made. The images or other third party material in this article are included in the article's Creative Commons licence, unless indicated otherwise in a credit line to the material. If material is not included in the article's Creative Commons licence and your intended use is not permitted by statutory regulation or exceeds the permitted use, you will need to obtain permission directly from the copyright holder. To view a copy of this licence, visit http://creativecommons.org/licenses/by/4.0/.

\section{References}

1. Friel RJ, Harris RA (2013) Ultrasonic additive manufacturing - a hybrid production process for novel functional products. Procedia CIRP 6:35-40

2. White DR (2003) Ultrasonic consolidation of aluminum tooling. Adv Mater Process 161(1):64-65

3. Sames WJ, List FA, Pannala S, Dehoff RR, Babu SS (2016) The metallurgy and processing science of metal additive manufacturing. Int Mater Rev 61(5):315-360

4. Zhang J, Song B, Wei Q, Bourell D, Shi Y (2019) A review of selective laser melting of aluminum alloys: processing, microstructure, property and developing trends. J Mater Sci Technol 35(2): 270-284

5. Yakout M, Elbestawi MA, Veldhuis SC (2018) On the characterization of stainless steel $316 \mathrm{~L}$ parts produced by selective laser melting. Int J Adv Manuf Technol 95(5):1953-1974

6. Murr LE, Gaytan SM, Ramirez DA, Martinez E, Hernandez J, Amato KN, Shindo PW, Medina FR, Wicker RB (2012) Metal fabrication by additive manufacturing using laser and electron beam melting technologies. J Mater Sci Technol 28(1):1-14

7. Bai Y, Williams CB (2018) Binder jetting additive manufacturing with a particle-free metal ink as a binder precursor. Mater Des 147: 146-156 
8. Shi T, Lu B, Shen T, Zhang R, Shi S, Fu G (2018) Closed-loop control of variable width deposition in laser metal deposition. Int $\mathrm{J}$ Adv Manuf Technol 97(9):4167-4178

9. Mudge RR, Wald NR (2007) Laser engineered net shaping advances additive manufacturing and repair. Weld J 86(1):44-48

10. Rodrigues TA, Duarte V, Miranda RM, Santos TG, Oliveira JP (2019) Current status and perspectives on wire and arc additive manufacturing (WAAM). Materials 12:1121

11. Kong CY, Soar RC, Dickens PM (2003) Characterisation of aluminium alloy 6061 for the ultrasonic consolidation process. Mater Sci Eng A 363(1-2):99-106

12. Kong CY, Soar RC, Dickens PM (2004) Optimum process parameters for ultrasonic consolidation of 3003 aluminium. J Mater Process Technol 146(2):181-187

13. Wu X, Liu T, Cai W (2015) Microstructure, welding mechanism, and failure of $\mathrm{Al} / \mathrm{Cu}$ ultrasonic welds. J Manuf Process 20:515-524

14. Sriraman MR, Babu SS, Short M (2010) Bonding characteristics during very high power ultrasonic additive manufacturing of copper. Scr Mater 62(8):560-563

15. Fujii HT, Endo H, Sato YS, Kokawa H (2018) Interfacial microstructure evolution and weld formation during ultrasonic welding of $\mathrm{Al}$ alloy to $\mathrm{Cu}$. Mater Charact 139:233-240

16. Yang Y, Ram GDJ, Stucker BE (2009) Bond formation and fiber embedment during ultrasonic consolidation. J Mater Process Technol 209(10):4915-4924

17. Levy A, Miriyev A, Sridharan N, Han T, Tuval E, Babu SS, Dapino MJ, Frage N (2018) Ultrasonic additive manufacturing of steel: method, post-processing treatments and properties. J Mater Process Technol 256:183-189

18. Kuo C-H, Sridharan N, Han T, Dapino MJ, Babu SS (2019) Ultrasonic additive manufacturing of 4130 steel using Ni interlayers. Sci Technol Weld Join 24(5):382-390

19. Sridharan N, Wolcott P, Dapino M, Babu SS (2016) Microstructure and texture evolution in aluminum and commercially pure titanium dissimilar welds fabricated using ultrasonic additive manufacturing. Scr Mater 117:1-5

20. Kaya İ, Cora ÖN, Acar D, Koç M (2018) On the formability of ultrasonic additive manufactured al-ti laminated composites. Metall Mater Trans A 49(10):5051-5064

21. Wolcott PJ, Sridharan N, Babu SS, Miriyev A, Frage N, Dapino MJ (2016) Characterisation of Al-Ti dissimilar material joints fabricated using ultrasonic additive manufacturing. Sci Technol Weld Join 21(2):114-123

22. Sridharan N, Wolcott P, Dapino M, Babu SS (2017) Microstructure and mechanical property characterisation of aluminium-steel joints fabricated using ultrasonic additive manufacturing AU. Sci Technol Weld Join 22(5):373-380

23. Hehr A, Dapino MJ (2015) Interfacial shear strength estimates of NiTi-Al matrix composites fabricated via ultrasonic additive manufacturing. Compos Part B 77:199-208

24. Hahnlen R, Dapino MJ (2014) NiTi-Al interface strength in ultrasonic additive manufacturing composites. Compos Part B 59:101108

25. Hehr A, Wenning J, Norfolk M, Sheridan J, Newman JA, Domack M (2019) Selective reinforcement of aerospace structures using ultrasonic additive manufacturing. J Mater Eng Perform 28(2): 633-640

26. Obielodan JO (2010) Fabrication of multi-material structures using ultrasonic consolidation and laser-engineered net shaping. In: Mechanical and aerospace engineering. Utah State University

27. Obielodan JO, Ceylan A, Murr LE, Stucker BE (2010) Multimaterial bonding in ultrasonic consolidation. Rapid Prototyp J 16(3):180-188

28. Li D, Soar R (2007) Optimum process parameters and influencing factors for embedding $\mathrm{SiC}$ fibres in $\mathrm{Al} 6061 \mathrm{O}$ matrix through ultrasonic consolidation. In: Proceedings of the Materials Science and Technology 2007 conference. Detroit, Michigan

29. Li DZ, Soar RC (2009) Characterization of process for embedding $\mathrm{SiC}$ fibers in $\mathrm{Al} 6061 \mathrm{O}$ matrix through ultrasonic consolidation. J Eng Mater Technol Trans ASME 131(2):021016

30. Kong CY, Soar RC, Dickens PM (2004) Ultrasonic consolidation for embedding SMA fibres within aluminium matrices. Compos Struct 66(1-4):421-427

31. Li J, Monaghan T, Masurtschak S, Bournias-Varotsis A, Friel RJ, Harris RA (2015) Exploring the mechanical strength of additively manufactured metal structures with embedded electrical materials. Mater Sci Eng A 639:474-481

32. Bournias-Varotsis A, Friel RJ, Harris RA, Engstrøm DS (2018) Ultrasonic additive manufacturing as a form-then-bond process for embedding electronic circuitry into a metal matrix. J Manuf Process 32:664-675

33. Mou CB et al (2008) Embedded fibre Bragg grating array sensors in aluminium alloy matrix by ultrasonic consolidation 19th International Conference on Optical Fibre Sensors, Pts 1 and 2, 7004: p 70044B

34. Mou CB et al (2009) Smart structure sensors based on embedded fibre Bragg grating arrays in aluminium alloy matrix by ultrasonic consolidation. Meas Sci Technol 20(3):034013

35. Hehr A, Norfolk M, Wenning J, Sheridan J, Leser P, Leser P, Newman JA (2018) Integrating fiber optic strain sensors into metal using ultrasonic additive manufacturing. JOM 70(3):315-320

36. Guo H, Gingerich MB, Headings LM, Hahnlen R, Dapino MJ (2019) Joining of carbon fiber and aluminum using ultrasonic additive manufacturing (UAM). Compos Struct 208:180-188

37. Hehr A, Norfolk M (2019) A comprehensive review of ultrasonic additive manufacturing. Rapid Prototyp J 26(3):445-458

38. Gujba AK, Medraj M (2020) Power ultrasonic additive manufacturing: process parameters, microstructure, and mechanical properties. Adv Mater Sci Eng 2020:1064870

39. Li DZ, Soar R (2009) Influence of sonotrode texture on the performance of an ultrasonic consolidation machine and the interfacial bond strength. J Mater Process Technol 209(4):1627-1634

40. Janaki Ram GD, Yang Y, Stucker BE (2006) Effect of process parameters on bond formation during ultrasonic consolidation of aluminum alloy 3003. J Manuf Syst 25(3):221-238

41. Wolcott PJ, Hehr A, Pawlowski C, Dapino MJ (2016) Process improvements and characterization of ultrasonic additive manufactured structures. J Mater Process Technol 233:44-52

42. Friel RJ, Johnson KE, Dickens PM, Harris RA (2010) The effect of interface topography for ultrasonic consolidation of aluminium. Mater Sci Eng A 527(16):4474-4483

43. Shimizu S, Fujii HT, Sato YS, Kokawa H, Sriraman MR, Babu SS (2014) Mechanism of weld formation during very-high-power ultrasonic additive manufacturing of $\mathrm{Al}$ alloy 6061. Acta Mater 74: 234-243

44. Johnson KE (2008) Interlaminar sub-grain refinement in ultrasonic consolidation. In: Wolfson School of Mechanical and Manufacturing Engineering, Loughborough University

45. Graff KF, Short M, Norfolk M (2010) Very high power ultrasonic additive manufacturing (VHP UAM) for advanced materials. In: Proc. SFF Symposium 2010, p 82

46. Milner DR, Rowe GW (1962) Fundamentals of solid-phase welding. Metall Rev 7(1):433-480

47. Mohamed HA, Washbur J (1975) Mechanism of solid state pressure welding. Weld J 9:302 s

48. Obielodan J, Stucker B (2014) A fabrication methodology for dualmaterial engineering structures using ultrasonic additive manufacturing. Int J Adv Manuf Technol 70(1):277-284

49. Domack MS, Baughman JM (2005) Development of nickeltitanium graded composition components. Rapid Prototyp J 11(1):41-51 
50. Janaki Ram GD, Robinson C, Yang Y, Stucker BE (2007) Use of ultrasonic consolidation for fabrication of multi-material structures. Rapid Prototyp J 13(4):226-235

51. Krüger S, Wagner G, Eifler D (2004) Ultrasonic welding of metal/ composite joints. Adv Eng Mater 6(3):157-159

52. Truog AG (2012) Bond improvement of $\mathrm{Al} / \mathrm{Cu}$ joints created by very high power ultrasonic additive manufacturing. In: Department of Mechanical and Aerospace Engineering. The Ohio State University, Columbus

53. Zhang W, Ao S, Oliveira JP, Li C, Zeng Z, Wang A, Luo Z (2020) On the metallurgical joining mechanism during ultrasonic spot welding of NiTi using a $\mathrm{Cu}$ interlayer. Scr Mater 178:414-417

54. Li C, Ao S, Oliveira JP, Cheng M, Zeng Z, Cui H, Luo Z (2020) Ultrasonic spot welded NiTi joints using an aluminum interlayer: microstructure and mechanical behavior. J Manuf Process 56: $1201-1210$

55. Mariani E, Ghassemieh E (2010) Microstructure evolution of 6061 $\mathrm{O} \mathrm{Al}$ alloy during ultrasonic consolidation: an insight from electron backscatter diffraction. Acta Mater 58(7):2492-2503

56. Dehoff RR, Babu SS (2010) Characterization of interfacial microstructures in 3003 aluminum alloy blocks fabricated by ultrasonic additive manufacturing. Acta Mater 58(13):4305-4315

57. Kulakov M, Rack HJ (2009) Control of 3003-H18 aluminum ultrasonic consolidation. J Eng Mater Technol 131(2):021006-021006-6

58. Han T, Kuo CH, Sridharan N, Headings LM, Babu SS, Dapino MJ (2020) Effect of preheat temperature and post-process treatment on the microstructure and mechanical properties of stainless steel 410 made via ultrasonic additive manufacturing. Mater Sci Eng A 769: 138457

59. Sriraman MR et al (2010) Bond characterization in very high power ultrasonic additive manufacturing. In: Proceedings of the Twenty First International Solid Freeform Fabrication Symposium. Austin, USA

60. Pal D, Stucker B (2013) A study of sub-grain formation in Al 3003 $\mathrm{H}-18$ foils undergoing ultrasonic additive manufacturing using a dislocation density based crystal plasticity finite element framework. J Appl Phys 113(20):203517
61. Obielodan JO et al (2009) Minimizing defects between adjacent foils in ultrasonically consolidated parts. J Eng Mater Technol 132(1):011006-011006-8

62. Fujii HT, Sriraman MR, Babu SS (2011) Quantitative evaluation of bulk and interface microstructures in Al-3003 alloy builds made by very high power ultrasonic additive manufacturing. Metall Mater Trans A 42(13):4045-4055

63. Langenecker B (1966) Effects of ultrasound on deformation characteristics of metals. IEEE Trans Sonics Ultrasonics SU13(1):1-8

64. Li DZ, Soar RC (2008) Plastic flow and work hardening of Al alloy matrices during ultrasonic consolidation fibre embedding process. Mater Sci Eng A 498(1-2):421-429

65. Sriraman MR, Gonser M, Fujii HT, Babu SS, Bloss M (2011) Thermal transients during processing of materials by very high power ultrasonic additive manufacturing. J Mater Process Technol 211(10):1650-1657

66. Sojiphan K (2015) Effects of very high power ultrasonic additive manufacturing process parameters on hardness, microstructure, and texture of aluminum 3003-H18 alloy, in Mechanical Engineering, The Ohio State University

67. Sojiphan K, Babu SKS, Manonukul A (2016) Effects of ultrasonic power on the hardness of aluminum 3003-H18 alloy. Weld J 95(6): $185 \mathrm{~s}-193 \mathrm{~s}$

68. Johnson K, Edmonds HC, Higginson RL, Harris RA (2011) New discoveries in ultrasonic consolidation nano-structures using emerging analysis techniques. Proc Inst Mech Eng L J Mater Des Appl 225(4):277-287

69. Schick DE (2009) Characterization of aluminum 3003 ultrasonic additive manufacturing, in welding engineering. The Ohio State University.

70. Schick DE et al (2010) Microstructural characterization of bonding interfaces in aluminum 3003 blocks fabricated by ultrasonic additive manufacturing. Weld J 89:105 s-115 s

Publisher's note Springer Nature remains neutral with regard to jurisdictional claims in published maps and institutional affiliations. 